\title{
Competing Jahn-Teller distortions and ferrimagnetic ordering in the geometrically frustrated system $\mathrm{Ni}_{1-x} \mathrm{Cu}_{x} \mathrm{Cr}_{2} \mathrm{O}_{4}$
}

\author{
M. Reehuis, ${ }^{1}$ M. Tovar, ${ }^{1}$ D. M. Többens, ${ }^{1}$ P. Pattison,,${ }^{2,3}$ A. Hoser, ${ }^{1}$ and B. Lake ${ }^{1}$ \\ ${ }^{1}$ Helmholtz-Zentrum Berlin für Materialien und Energie, D-14109 Berlin, Germany \\ ${ }^{2}$ SNBL at ESRF, BP 220, F-38042 Grenoble Cedex 9, France \\ ${ }^{3}$ Laboratory of Crystallography, Swiss Federal Institute of Technology, BSP-Dorigny, CH-1015 Lausanne, \\ Switzerland
}

Competing Jahn-Teller distortions combined with geometrical frustration give rise to a rich phase diagram as a function of $x(\mathrm{Cu})$ and temperature in the spinel system $\mathrm{Ni}_{1-x} \mathrm{Cu}_{x} \mathrm{Cr}_{2} \mathrm{O}_{4}$. The Jahn-Teller distortion of the end members acts in opposite ways with an elongation of the $\mathrm{NiO}_{4}$ tetrahedra resulting in a structural transition at $T_{\mathrm{S} 1}=317 \mathrm{~K}$ in $\mathrm{NiCr}_{2} \mathrm{O}_{4}$, but a flattening in the $\mathrm{CuO}_{4}$ tetrahedra at $T_{\mathrm{S} 1}=846 \mathrm{~K}_{\text {in }} \mathrm{CuCr}_{2} \mathrm{O}_{4}$, in both cases the symmetry is lowered from cubic $(F d \overline{3} m)$ to tetragonal $\left(I 4_{1} / a m d\right)$ on cooling. In order to follow the influence of Jahn-Teller active $\mathrm{Ni}^{2+}$ and $\mathrm{Cu}^{2+}$ ions on the structural and magnetic properties of chromium spinels we have investigated a series of samples of $\mathrm{Ni}_{1-x} \mathrm{Cu}_{x} \mathrm{Cr}_{2} \mathrm{O}_{4}$ by $x$-ray and neutron powder diffraction. In the critical range $0.10<x(\mathrm{Cu})<0.20$ strong orthorhombic distortions were observed, where competing Jahn-Teller activities between the $\mathrm{Cu}^{2+}$ and $\mathrm{Ni}^{2+}$ ions result in distortions along both the $a$ and $c$ axes. For $\mathrm{Ni}_{0.85} \mathrm{Cu}_{0.15} \mathrm{Cr}_{2} \mathrm{O}_{4}$ the orthorhombic structure $(F d d d)$ is stabilized up to $T_{\mathrm{S} 2}=368(2) \mathrm{K}$ close to the first structural phase transition at $T_{\mathrm{S} 1}=374(2) \mathrm{K}$. A ferrimagnetic spin alignment of the $\mathrm{Ni} / \mathrm{Cu}$ and chromium atoms sets in at much lower temperature $T_{\mathrm{C}}=95 \mathrm{~K}$ in this compound. The end members $\mathrm{NiCr}_{2} \mathrm{O}_{4}$ and $\mathrm{CuCr}_{2} \mathrm{O}_{4}$ undergo this ferrimagnetic transition at $T_{\mathrm{C}}=74$ and $135 \mathrm{~K}$, respectively. These transitions are accompanied by the structural change to the orthorhombic symmetry which relieves the frustration. $\mathrm{NiCr}_{2} \mathrm{O}_{4}$ and $\mathrm{Ni}_{0.85} \mathrm{Cu}_{0.15} \mathrm{Cr}_{2} \mathrm{O}_{4}$ undergo a second magnetic transition at $T_{\mathrm{M} 2}=24$ and $67 \mathrm{~K}$ due to a superimposed antiferromagnetic ordering of the $\mathrm{Cr}$ moments resulting in a non-collinear magnetic structure. In the system $\mathrm{Ni}_{1-x} \mathrm{Cu}_{x} \mathrm{Cr}_{2} \mathrm{O}_{4}$ the magnetic transitions $T_{\mathrm{C}}$ and $T_{\mathrm{M} 2}$ merge with increasing copper content up to $x(\mathrm{Cu}) \sim 0.5$. For the Ni rich chromites geometrical frustration causes a strong reduction of the chromium moments, where magnetic long-range order coexists with a disordered spin-liquid-like or a reentrant-spin-glass-like state. This investigation provides insight into the interplay between the Jahn-Teller effect, geometrical frustration and long-range magnetic order in these complex systems.

PACS number(s): 61.05.fm, 61.66.Fn, 71.70.Ej, 75.50.Gg 


\section{INTRODUCTION}

Investigations of magnetostructural coupling in geometrically frustrated magnets have invoked a broad interest, especially where structural distortions lift the large ground state degeneracy allowing long-range magnetic order. In normal spinels with the general formula $A B_{2} \mathrm{O}_{4}$ the $A^{2+}$ cation occupies the tetrahedral site ( $A$ site), while the $B^{3+}$ cation occupies the octahedral site ( $B$ site). The $B^{3+}$ cations form a corner-sharing tetrahedral network (pyrochlore lattice), where the spins are often governed by strong geometrical frustration. Already in the 1950s theoretical concepts of long-range ordering were proposed in pyrochlore lattices. ${ }^{1,2}$ Transition-metal spinels, where $A$ is diamagnetic $\left(A=\mathrm{Mg}^{2+}, \mathrm{Zn}^{2+}, \mathrm{Cd}^{2+}\right.$, and $\left.\mathrm{Hg}^{2+}\right)$ are ideal models to study the interactions between spin, lattice, and orbital degrees of freedom affected by geometrical frustration. ${ }^{3}$ In the system $A \mathrm{~V}_{2} \mathrm{O}_{4}$, where the $\mathrm{V}^{3+}$-ions have an orbital degree of freedom with $3 d^{2}$ configuration, the tetragonal compression causes the $t_{2 g}$ levels to split into a lower $d_{x y}$ level and a twofold degenerate $d_{y z} / d_{x z}$ level. Electronic energy can thus be gained by cooperative distortion of the $\mathrm{VO}_{6}$ octahedra through the Jahn-Teller effect. For $\mathrm{MgV}_{2} \mathrm{O}_{4}$ and $\mathrm{ZnV}_{2} \mathrm{O}_{4}$ this transition sets in at $T_{\mathrm{S}}=65$ and $51 \mathrm{~K}$, respectively. ${ }^{4,5}$ Long-range antiferromagnetic ordering occurs at lower temperature at $T_{\mathrm{N}}=42 \mathrm{~K}\left(\mathrm{MgV}_{2} \mathrm{O}_{4}\right)$ and $T_{\mathrm{N}}=40$ $\mathrm{K}\left(\mathrm{ZnV}_{2} \mathrm{O}_{4}\right)^{4,5}$ In chromium spinels the $\mathrm{Cr}^{3+}$ ions have $3 d^{3}$ configuration, where the $t_{2 g}$ levels are half filled. In this configuration cooperative distortions of the $\mathrm{CrO}_{6}$ octahedra through the Jahn-Teller effect should be absent. However, in the highly frustrated chromites $\mathrm{MgCr}_{2} \mathrm{O}_{4}$, $\mathrm{ZnCr}_{2} \mathrm{O}_{4}, \mathrm{CdCr}_{2} \mathrm{O}_{4}$, and $\mathrm{HgCr}_{2} \mathrm{O}_{4}$ antiferromagnetic ordering sets in at the Néel temperatures $T_{\mathrm{N}}=12.9,12.5,7.8$, and $5.8 \mathrm{~K}$, respectively. ${ }^{6-9}$ Due to the presence of magnetoelastic effects a change to a lower crystal structure symmetry was found at these temperatures which relieve the frustration and enabling the magnetic order. ${ }^{7,8}$ For $\mathrm{HgCr}_{2} \mathrm{O}_{4}$ almost degenerated spinexcitation modes were discovered by powder inelastic neutron scattering indicating the coexistence of a quantum spin liquid with magnetic long-range order as ground states well below $T_{\mathrm{N} .}{ }^{10}$

In spinels, where $A^{2+}$ is a magnetic ion, the $A^{2+}-\mathrm{O}-\mathrm{Cr}^{3+}$-interaction is usually collectively stronger than the frustrated interactions between the $\mathrm{Cr}^{3+}$-ions. In the multiferroic spinel $\mathrm{CoCr}_{2} \mathrm{O}_{4}$, where neither $\mathrm{Co}^{2+}$ nor $\mathrm{Cr}^{3+}$ are Jahn-Teller active, the magnetic ordering consists of a ferrimagnetic component and a spiral component below $T_{\mathrm{C}}=93 \mathrm{~K} .{ }^{11}$ The ferrimagnetic component exhibits long-range order, while the spiral component exhibits short-range order, which transforms to long-range order at $T_{\mathrm{M} 2}=31 \mathrm{~K} .{ }^{12}$ Upon this transition Yamasaki et al. (Ref. 13) have demonstrated the presence of ferroelectricity based on the conical spin 
modulation. In $\mathrm{NiCr}_{2} \mathrm{O}_{4}$ and $\mathrm{CuCr}_{2} \mathrm{O}_{4}$ strong Jahn-Teller activities were found on the $A$ sites resulting in an elongation of the $\mathrm{NiO}_{4}$ tetrahedra and a flattening of the $\mathrm{CuO}_{4}$ tetrahedra along the tetragonal $c$ axis (Fig. 1), where the cubic spinel structure ( $F d \overline{3} m$ ) changes to the nextlower symmetric tetragonal structure with the space group $I_{1} /$ amd. ${ }^{14-22}$ For $\mathrm{NiCr}_{2} \mathrm{O}_{4}$ this transition was observed at 310 and $320 \mathrm{~K}$, while for $\mathrm{CuCr}_{2} \mathrm{O}_{4}$ it was observed at much higher temperature at 853 and $865 \mathrm{~K} \cdot{ }^{20,21,23,24}$ Susceptibility measurements of $\mathrm{NiCr}_{2} \mathrm{O}_{4}$ showed that a ferrimagnetic transition occurs at $T_{\mathrm{C}}=74 \mathrm{~K}$ followed by a second magnetic transition at $T_{\mathrm{M} 2}$ $=31 \mathrm{~K} .{ }^{25}$ Similar temperatures $\left(T_{\mathrm{C}}=75 \mathrm{~K}, T_{\mathrm{M} 2}=29 \mathrm{~K}\right)$ were found by means of specific-heat measurements. ${ }^{23}$ For $\mathrm{CuCr}_{2} \mathrm{O}_{4}$ a very similar ferrimagnetic transition could be found in the range between 122 and $157 \mathrm{~K} .{ }^{18,21,22,24}$ Nevertheless, susceptibility measurements of $\mathrm{CuCr}_{2} \mathrm{O}_{4}$ did not reveal any second magnetic transition. ${ }^{21,26,27}$ Suchomel et al. (Ref. 22) finally showed by high-resolution $x$-ray synchrotron powder diffraction that the change from the tetragonal to an orthorhombic structure (space group $F d d d$ ) occurs concurrently with the onset of ferrimagnetic order.

The magnetic structures of $\mathrm{NiCr}_{2} \mathrm{O}_{4}$ and $\mathrm{CuCr}_{2} \mathrm{O}_{4}$ were investigated earlier by neutron powder diffraction. ${ }^{18,25,28}$ The magnetic moments of $\mathrm{NiCr}_{2} \mathrm{O}_{4}$ are composed of a ferrimagnetic (longitudinal) and antiferromagnetic (transverse component, where the magnetic structures were described by the propagation vectors $\boldsymbol{k}_{1}=0$ and $\boldsymbol{k}_{2}=(0,0,1)$, respectively. However two different types of spin structures presented in Refs. 25 and 28 gave rise to controversial discussions. In contrast to the nickel chromite both the ferrimagnetic and antiferromagnetic ordering of $\mathrm{CuCr}_{2} \mathrm{O}_{4}$ are describable with the same propagation vector $\boldsymbol{k}=0 .{ }^{18}$ However, it was not possible to distinguish between two different models of triangular spin arrangements. ${ }^{18}$ All these inconsistencies led us to reinvestigate the magnetic structures of $\mathrm{NiCr}_{2} \mathrm{O}_{4}$ and $\mathrm{CuCr}_{2} \mathrm{O}_{4}$, since knowledge of their magnetic structures is essential for an understanding of the interplay between Jahn-Teller distortions and magnetic forces in the solid solution series $\mathrm{Ni}_{1-x} \mathrm{Cu}_{x} \mathrm{Cr}_{2} \mathrm{O}_{4}$.

The main purpose of this paper is to provide a more complete basis for a theoretical description of the rather complex magnetic states in chromium spinels. Of particular interest is to investigate the interplay between coexisting ferri- and antiferromagnetic spin structures and disordered spin states, as well as the influence on the magnetic $\mathrm{Cr}^{3+}$ ions forming a more or less distorted pyrochlore lattice. Therefore neutron and $x$-ray powder diffraction was used to carry out a comprehensive investigation of the crystal and magnetic structures of a series of samples in the system $\mathrm{Ni}_{1-x} \mathrm{Cu}_{x} \mathrm{Cr}_{2} \mathrm{O}_{4}$. 


\section{EXPERIMENTAL DETAILS}

Powder samples of $\mathrm{Ni}_{1-x} \mathrm{Cu}_{x} \mathrm{Cr}_{2} \mathrm{O}_{4}$ were prepared by the precursor method using $\mathrm{Cu}$ (II)hydroxide carbonate (Merck), $\mathrm{Ni}$ (II)-hydroxide carbonate (Merck) and $\mathrm{Cr}$ (III) nitrate (Alfa Aesar) as starting materials. We prepared several samples in the system $\mathrm{Ni}_{1-x} \mathrm{Cu}_{x} \mathrm{Cr}_{2} \mathrm{O}_{4}$ in steps of $\Delta x(\mathrm{Cu})=0.10$; in the critical range $0.10 \leq x(\mathrm{Cu}) \leq 0.20$ samples in steps of $\Delta x(\mathrm{Cu})=$ 0.02 , as well as two more samples with $x(\mathrm{Cu})=0.25$ and 0.05 . Mixed powders of the starting materials were reacted in a corundum crucible at temperatures up to $600 \mathrm{~K}$. The resulting products were pulverized again and sintered at $1200 \mathrm{~K}$ for $24 \mathrm{~h}$. In order to improve the homogeneity of the samples they were annealed for another 5 days at $1200 \mathrm{~K}$. The sample quality was checked by $x$-ray powder diffractometer (Bruker D8 advance) using $\mathrm{Cu}-\mathrm{K} \alpha$ radiation. The $x$-ray powder patterns of the different samples occasionally showed minor amounts of $\mathrm{Cr}_{2} \mathrm{O}_{3}(<5.1 \%)$ and $\mathrm{NiO}(<0.6 \%)$. For further investigations of the crystal structure between 10 and $350 \mathrm{~K}$ we used a Guinier diffractometer Huber $645\left(\mathrm{Cu}-\mathrm{Ka}_{1}, \lambda=\right.$ $1.54051 \AA$ ). On both diffractometers $x$-ray powder data were collected in the $2 \theta$-range between 15 and $100^{\circ}$. In order to find a conclusive answer about the crystal structure symmetry of $\mathrm{Ni}_{0.85} \mathrm{Cu}_{0.15} \mathrm{Cr}_{2} \mathrm{O}_{4}$, we have performed a synchrotron powder diffraction study at the European Synchrotron Radiation Facility (ESRF) in Grenoble using the wavelength $\lambda=$ $0.6888 \AA$ A. A complete high-resolution powder pattern of $\mathrm{Ni}_{0.85} \mathrm{Cu}_{0.15} \mathrm{Cr}_{2} \mathrm{O}_{4}$ was collected with the PILATUS at the Swiss-Norwegian beam line with a $2 \theta$ range between 1 and $46^{\circ}$. This instrument uses a pixel area detector with flexible goniometry.

The influence of copper substitution in the system $\mathrm{Ni}_{1-x} \mathrm{Cu}_{x} \mathrm{Cr}_{2} \mathrm{O}_{4}$ on the phase transition temperatures was investigated using differential scanning calorimetry (DSC, PerkinElmer Pyris 1) in the temperature range between 323 and $873 \mathrm{~K}$ with heating and cooling rate of 20 ${ }^{\circ} \mathrm{C} \min ^{-1}$. Further investigations of structural and magnetic phase transitions were carried out by neutron powder diffraction down to $2 \mathrm{~K}$. This technique also allowed us to determine in detail the crystal and magnetic structures in the system $\mathrm{Ni}_{1-x} \mathrm{Cu}_{x} \mathrm{Cr}_{2} \mathrm{O}_{4}$. Neutron powder diffraction experiments were carried out on the instruments E6 and E9 (Ref. 29) at the BER II reactor of the Helmholtz-Zentrum Berlin (HZB), using pyrolytic graphite and $\mathrm{Ge}$ monochromators selecting the neutron wavelengths $\lambda=2.442 \AA$ and $\lambda=1.7982 \AA$, respectively. At room temperature complete powder patterns $\left(8^{\circ} \leq 2 \theta \leq 150^{\circ}\right)$ were collected on E9 in the full range $0 \leq x(\mathrm{Cu}) \leq 1$ in steps of $\Delta x=0.10$ and at $2 \mathrm{~K}$ powder patterns of samples with $x(\mathrm{Cu})=0,0.40,0.60,0.80,1$. A detailed study of the crystal and magnetic 
structure was carried out for end member $\mathrm{NiCr}_{2} \mathrm{O}_{4}$ and the mixed chromite $\mathrm{Ni}_{0.85} \mathrm{Cu}_{0.15} \mathrm{Cr}_{2} \mathrm{O}_{4}$. A large number of powder patterns was collected on E6 $\left(8^{\circ} \leq 2 \theta \leq 137^{\circ}\right)$ and E9 $\left(8^{\circ} \leq 2 \theta \leq\right.$ $150^{\circ}$ ) in the temperature range between $2 \mathrm{~K}$ and $475 \mathrm{~K}$. Rietveld refinements of the powder diffraction data were carried out with the program FullProf..$^{30}$ For the $x$-ray data we used the atomic scattering factors provided by the program; for the neutron data we used the nuclear scattering lengths $b(\mathrm{O})=5.805 \mathrm{fm}, b(\mathrm{Cr})=3.635 \mathrm{fm}, b(\mathrm{Ni})=10.3 \mathrm{fm}$, and $b(\mathrm{Cu})=7.818 \mathrm{fm}$, respectively. ${ }^{31}$ The magnetic form factors of the $\mathrm{Cr}^{3+}, \mathrm{Ni}^{2+}$ and $\mathrm{Cu}^{2+}$ ions were taken from Ref. 32.

\section{RESULTS AND DISCUSSION}

\section{A. Structural properties of $\mathrm{Ni}_{1-x} \mathrm{Cu}_{x} \mathrm{Cr}_{2} \mathrm{O}_{4}$ at room temperature}

We have started our study by investigating the variation of lattice parameters of several samples of the system $\mathrm{Ni}_{1-x} \mathrm{Cu}_{x} \mathrm{Cr}_{2} \mathrm{O}_{4}$ by $x$-ray powder diffraction. In order to get comparable lattice parameters for the cubic (space group $F d \overline{3} m$ ), tetragonal $\left(I 4_{1} / a m d\right)$, and orthorhombic $(F d d d)$ phases we generally used in the present work the setting of the pseudocubic $F$ centered unit cell (labeled as $a, b$, and $c$ ). In this regard it has to be noted that the dimensions of the tetragonal cell are $a_{\mathrm{t}} \times b_{\mathrm{t}} \times c_{\mathrm{t}}=a / \sqrt{ } 2 \times b / \sqrt{ } 2 \times c$. Fig. 2 shows that a strong structural change occurs in the critical range $0.10 \leq x(\mathrm{Cu}) \leq 0.20$. This is in excellent agreement with the result of an earlier $x$-ray diffraction study. ${ }^{16}$ Outside this critical range one finds a strong stabilization of the Jahn-Teller effect on the A-site, where the different electronic configurations of the $\mathrm{Ni}^{2+}$ and $\mathrm{Cu}^{2+}$ ions lead to the ratios $c / a>1$, and $c{ }^{\prime} / a^{\prime}<1$, respectively. It is obvious from Fig. 2 that a change from the state $a=b<c$ (Ni-rich) to the state $a<b=c$ (Cu-rich) occurs by a continuous increase of $b$ with increasing $\mathrm{Cu}$ content. A consistent description of the whole system requires that the $c$ and $c$ ' axes of the two tetragonal end members lie in different directions. Thus we used for the copper-rich compounds the tetragonal setting $a<b=c$, instead of the standard setting $c^{\prime}<b^{\prime}=a^{\prime}$ (with $b=b^{\prime}$ ), where $a$ is now the tetragonal axis. An orthorhombic splitting $(a<b<c)$ could be observed in the range $0.10 \leq x(\mathrm{Cu}) \leq 0.30$, where the strongest orthorhombic distortion was found for the chromite $\mathrm{Ni}_{0.85} \mathrm{Cu}_{0.15} \mathrm{Cr}_{2} \mathrm{O}_{4}$.

Closer inspection of the powder patterns of all investigated chromites showed that only for $\mathrm{Ni}_{0.85} \mathrm{Cu}_{0.15} \mathrm{Cr}_{2} \mathrm{O}_{4}$ several Bragg reflections are considerably broadened. The strongest 
broadening was found for the reflection series $h 00,0 k 0$, and $00 \ell$. In order to exclude the presence of a further symmetry reduction into a monoclinic or triclinic structure we collected a high-resolution synchrotron powder pattern of this chromite. The data analysis showed no additional peak splitting, but the peak broadening of particular Bragg reflections could be confirmed. In Fig. 3 we present the result of a simulation using the refined profile-function parameters obtained for the standard $\mathrm{LaB}_{6}$. It can be seen that the reflection 222 essentially shows the same resolution as that of $\mathrm{LaB}_{6}$, representing the instrumental resolution, whereas the $h 00,0 k 0$, and $00 \ell$ show an especially strong peak broadening. This behavior is probably correlated with the strong peak splitting of the cubic reflection $h 00$ into the orthorhombic reflections $h 00,0 k 0$, and $00 \ell$. On the other hand reflections of the type hhh do not show any peak splitting in the orthorhombic symmetry, and consequently their peak shapes remain unchanged. Such peak broadening only could be observed in $\mathrm{Ni}_{0.85} \mathrm{Cu}_{0.15} \mathrm{Cr}_{2} \mathrm{O}_{4}$, while for the end member $\mathrm{CuCr}_{2} \mathrm{O}_{4}$ no peak broadening of the series $h 00,0 k 0$, and $00 \ell$ was found despite the fact that the tetragonal axis is strongly reduced of about $10 \%$. This led us to the conclusion that a strongly anisotropic strain broadening in $\mathrm{Ni}_{0.85} \mathrm{Cu}_{0.15} \mathrm{Cr}_{2} \mathrm{O}_{4}$ is based on competing Jahn-Teller effects acting along particular directions along the $a$ and $c$ axes (elongated $\mathrm{NiO}_{4}$ and flattened $\mathrm{CuO}_{4}$ tetrahedra). The crystal structure of $\mathrm{Ni}_{0.85} \mathrm{Cu}_{0.15} \mathrm{Cr}_{2} \mathrm{O}_{4}$ was successfully refined by the use of additional strain parameters provided by the FullProf program. ${ }^{30}$ This resulted in an improvement of the quality of the difference pattern $\left(I_{\mathrm{obs}}-I_{\mathrm{cal}}\right)$ as well as in a reduction of the standard deviations of the lattice and atomic parameters. However no significant changes of these parameters were found in comparison with the standard refinements. In an earlier work a theory of the cooperative Jahn-Teller effect was developed for the purpose of discussing the spontaneous crystal distortions in mixed chromites. ${ }^{33}$ This theory explains successfully various features of the phase diagrams of mixed chromites such as the concentration dependences of transition temperatures and the magnitude of the distortions, as well as the appearance of an orthorhombic phase.

\section{B. Low-temperature crystal structure of $\mathrm{Ni}_{1-x} \mathrm{Cu}_{x} \mathrm{Cr}_{2} \mathrm{O}_{4}$}

The crystal structure of the end members $\mathrm{NiCr}_{2} \mathrm{O}_{4}$ and $\mathrm{CuCr}_{2} \mathrm{O}_{4}$ was investigated earlier

by synchrotron powder diffraction. ${ }^{22}$ At low temperature $(10 \mathrm{~K})$ both compounds showed an orthorhombic splitting, where the splitting of $\mathrm{CuCr}_{2} \mathrm{O}_{4}(c / a=1.00087)$ was found to be less pronounced than that of $\mathrm{NiCr}_{2} \mathrm{O}_{4}(c / a=1.00176) .{ }^{22}$ In the present work we have investigated 
the crystal structure of several chromites of the system $\mathrm{Ni}_{1-x} \mathrm{Cu}_{x} \mathrm{Cr}_{2} \mathrm{O}_{4}$ at $2 \mathrm{~K}$ by neutron powder diffraction. In agreement with Ref. 22 the low-temperature crystal structure could be successfully refined in the orthorhombic space group $F d d d$ (No. 70) for samples with a copper content up to $x(\mathrm{Cu})=0.40$. Using origin choice 2 of $F d d d$ (given in Ref. 34) the atoms are located at the following Wyckoff positions: $\mathrm{Ni} / \mathrm{Cu}$ at $8 a(1 / 8,1 / 8,1 / 8), \mathrm{Cr}$ at $16 d(1 / 2,1 / 2,1 / 2)$, and $32 h(x, y, z)$. For the copper-rich chromites with $x(\mathrm{Cu})>0.40$ eventual orthorhombic splitting was below the instrumental resolution of E9. Therefore for these samples the lattice parameters $b$ and $c$ as well as the positional parameters $y(\mathrm{O})$ and $z(\mathrm{O})$ were constrained to be equal during the refinements. This assumption is not unjustified, as from synchrotron powder data of Suchomel et al. (Ref. 22) these positional parameters of the oxygen atoms were indeed found to be equal $[y(\mathrm{O})=z(\mathrm{O})=0.2675(2)]$. For all samples the Rietveld refinements resulted in very satisfactory residuals $R_{F} \leq 0.023$ (defined as $R_{F}=\sum|| F_{\text {obs }}|-| F_{\text {calc }}|| / \sum\left|F_{\text {obs }}\right|$ ). The results of the refinements are summarized in Table I. Further the neutron powder patterns of $\mathrm{NiCr}_{2} \mathrm{O}_{4}, \mathrm{Ni}_{0.85} \mathrm{Cu}_{0.15} \mathrm{Cr}_{2} \mathrm{O}_{4}$, and $\mathrm{CuCr}_{2} \mathrm{O}_{4}$ collected at $2 \mathrm{~K}$ are shown in Fig. 4.

In this section we want to point out some systematic structural changes in the system $\mathrm{Ni}_{1-x} \mathrm{Cu}_{x} \mathrm{Cr}_{2} \mathrm{O}_{4}$ at $2 \mathrm{~K}$. Despite the fact that the end members $\mathrm{NiCr}_{2} \mathrm{O}_{4}$, and $\mathrm{CuCr}_{2} \mathrm{O}_{4}$ show an elongation (along $c$ ) and a flattening (along $a$ ) of the $\mathrm{NiO}_{4}$ and $\mathrm{CuO}_{4}$ tetrahedra, respectively, the crystal structures of both can be described in the orthorhombic space group $F d d d .^{22}$ Over the whole composition range of the system $\mathrm{Ni}_{1-x} \mathrm{Cu}_{x} \mathrm{Cr}_{2} \mathrm{O}_{4}$ a continuous description is possible, where the $a$ parameter is always the shortest one, and the $c$ parameter always the largest (Table I). In accordance with the room temperature data (Fig. 2), also at $2 \mathrm{~K}$ it is the $b$ parameter that undergoes the strongest change. Here the $b$ parameter almost reaches the values of $a$ and $c$ in the Ni-rich and $\mathrm{Cu}$-rich chromites, respectively. As expected we observed the strongest structural changes on the A-sites due to competing Jahn-Teller activities of the $\mathrm{Ni}^{2+}$ and $\mathrm{Cu}^{2+}$ cations. In the orthorhombic structure one finds three different tetrahedron angles, where the bisectors of $\angle_{a}(\mathrm{O}-A-\mathrm{O}), \angle_{b}(\mathrm{O}-A-\mathrm{O})$, and $\angle_{c}(\mathrm{O}-A-\mathrm{O})$ correspond to the $a, b$, and $c$ axes, respectively. In the ideal tetragonal structure of the end members $\mathrm{NiCr}_{2} \mathrm{O}_{4}$ and $\mathrm{CuCr}_{2} \mathrm{O}_{4}$ one finds the conditions $\angle{ }_{a}(\mathrm{O}-A-\mathrm{O})=\angle{ }_{b}(\mathrm{O}-A-\mathrm{O})>\angle{ }_{c}(\mathrm{O}-A-\mathrm{O})$, and $\angle{ }_{a}(\mathrm{O}-A-\mathrm{O})>$ $\angle_{b}(\mathrm{O}-A-\mathrm{O})=\angle_{c}(\mathrm{O}-A-\mathrm{O})$, respectively. In Table $\mathrm{I}$ it can be seen that the strongest changes were found for the angles $\angle{ }_{a}(\mathrm{O}-A-\mathrm{O})$, and $\angle{ }_{b}(\mathrm{O}-A-\mathrm{O})$, where $\angle{ }_{a}(\mathrm{O}-A-\mathrm{O})$ increases, and $\angle_{b}(\mathrm{O}-A-\mathrm{O})$ decreases by about 10 degrees with increasing copper content. On the other hand the angle $\angle_{c}$ only varies moderately in the range between 102.74 and $105.03^{\circ}$. Here it is important to note that the tetrahedral angle $\angle_{a}(\mathrm{O}-A-\mathrm{O})$ is always the largest in the system 
$\mathrm{Ni}_{1-x} \mathrm{Cu}_{x} \mathrm{Cr}_{2} \mathrm{O}_{4}$. Interestingly the bond lengths in the $A \mathrm{O}_{4}$ tetrahedra are rather stable: $d(A-\mathrm{O})$ only varies in the limited range between 1.961 and $1.969 \AA$, and the same tendency was found for the bond lengths $d(\mathrm{Cr}-\mathrm{O})$ in the $\mathrm{CrO}_{6}$ octahedra, where all the three different bond lengths $d_{a}(\mathrm{Cr}-\mathrm{O}), d_{b}(\mathrm{Cr}-\mathrm{O})$, and $d_{c}(\mathrm{Cr}-\mathrm{O})$ are in the range 1.977 to $1.992 \AA$. At this point we can conclude that no significant Jahn-Teller distortion could be found in the $\mathrm{CrO}_{6}$ octahedra down to very low temperature. It has to be mentioned that the bond lengths $d_{a}(\mathrm{Cr}-\mathrm{O}), d_{b}(\mathrm{Cr}-$ $\mathrm{O})$, and $d_{c}(\mathrm{Cr}-\mathrm{O})$ are almost parallel to the $a, b$, and $c$ axes. In the $\mathrm{CrO}_{6}$ units the change of the three different octahedral angles $\angle 1(\mathrm{O}-\mathrm{Cr}-\mathrm{O}), \angle_{2}(\mathrm{O}-\mathrm{Cr}-\mathrm{O})$, and $\angle_{3}(\mathrm{O}-\mathrm{Cr}-\mathrm{O})$ are much less pronounced. Here one only finds the tendency that $\angle_{1}$ decreases ( $\angle_{2}$ increases) of about 2-3 degrees with increasing copper content, whereas for $\angle 3$ the changes are less than $0.7^{\circ}$.

\section{Structural and magnetic phase transitions of $\mathrm{Ni}_{1-x} \mathrm{Cu}_{x} \mathrm{Cr}_{2} \mathrm{O}_{4}$}

We now discuss the sequence of structural and magnetic phase transitions in the solid solution series $\mathrm{Ni}_{1-x} \mathrm{Cu}_{x} \mathrm{Cr}_{2} \mathrm{O}_{4}$. Here we focus on the structural and magnetic phase transitions of $\mathrm{NiCr}_{2} \mathrm{O}_{4}$, and the mixed chromites $\mathrm{Ni}_{0.85} \mathrm{Cu}_{0.15} \mathrm{Cr}_{2} \mathrm{O}_{4}$, and $\mathrm{Ni}_{0.80} \mathrm{Cu}_{0.20} \mathrm{Cr}_{2} \mathrm{O}_{4}$ lying in the critical range $0.10 \leq x(\mathrm{Cu}) \leq 0.30$. Due to the fact that both the tetragonal and orthorhombic distortions are strongly pronounced in the two mixed chromites their individual lattice parameters could determined with good accuracy. From the temperature dependence of the lattice parameters the structural phase transition temperatures $T_{\mathrm{S} 1}$ (cubic to tetragonal) and $T_{\mathrm{S} 2}$ (tetragonal to orthorhombic) were determined. In Fig. 5 it can be seen that the orthorhombic structure of $\mathrm{Ni}_{0.85} \mathrm{Cu}_{0.15} \mathrm{Cr}_{2} \mathrm{O}_{4}$ is well stabilized up to a relatively high temperature that is very close to the first structural phase transition at $T_{\mathrm{S} 1}=374(2) \mathrm{K}$. Closer inspection shows that the lattice parameters $a$ and $b$ already become indistinguishable at $T_{\mathrm{S} 2}=368(2) \mathrm{K}$, indicating the presence of the tetragonal phase, which is stable in a narrow temperature range of only 6 degrees $(a=b<c)$. As it can be seen from Fig. 5, a slight increase of the copper level from $x(\mathrm{Cu})=0.15$ to 0.20 results in a strong expansion of the tetragonal phase range from $231(2)$ to 403(2) K. It is interesting to see that the lattice parameters $b$ and $c$ of $\mathrm{Ni}_{0.80} \mathrm{Cu}_{0.20} \mathrm{Cr}_{2} \mathrm{O}_{4}$ become identical in the tetragonal phase, where one finds $a<b=c$. For the end member $\mathrm{NiCr}_{2} \mathrm{O}_{4}$ it was found that a transition from the cubic to the tetragonal structure sets in at $T_{\mathrm{S} 1}=$ $317(2) \mathrm{K}$ followed by a structural change into the orthorhombic structure at $T_{\mathrm{S} 2}=74(2) \mathrm{K}$. For this compound the tetragonal distortion is much stronger pronounced than the 
orthorhombic distortion. The transition temperatures observed in this work are in good agreement with those given earlier..$^{20,22,23,25}$

In order to investigate in detail the magnetic phase transitions of $\mathrm{NiCr}_{2} \mathrm{O}_{4}$, $\mathrm{Ni}_{0.85} \mathrm{Cu}_{0.15} \mathrm{Cr}_{2} \mathrm{O}_{4}$, and $\mathrm{Ni}_{0.80} \mathrm{Cu}_{0.20} \mathrm{Cr}_{2} \mathrm{O}_{4}$ we have followed the temperature dependence of particular magnetic reflections (Fig. 6). $\mathrm{NiCr}_{2} \mathrm{O}_{4}$ shows a spontaneous increase of magnetic intensity at the position of the reflection 111 indicating the onset of ferrimagnetic ordering of the nickel and chromium. This magnetic transition sets in practically at the same temperature $T_{\mathrm{S} 2}=74(2) \mathrm{K}$, where the transition from the tetragonal into the orthorhombic structure was found. This is in agreement with the result of Suchomel et al., where it was claimed that the second structural transition is accompanied by the onset of ferrimagnetic ordering $\left(T_{\mathrm{S} 2}=\right.$ $\left.T_{\mathrm{C}}\right){ }^{22}$ The ferrimagnetic transitions of $\mathrm{Ni}_{0.85} \mathrm{Cu}_{0.15} \mathrm{Cr}_{2} \mathrm{O}_{4}$ and $\mathrm{Ni}_{0.80} \mathrm{Cu}_{0.20} \mathrm{Cr}_{2} \mathrm{O}_{4}$ were found to be at higher temperature at $T_{\mathrm{C}}=85(3) \mathrm{K}$ and $T_{\mathrm{C}}=95(3) \mathrm{K}$, respectively. In contrast to $\mathrm{NiCr}_{2} \mathrm{O}_{4}$ these transitions were found to be well below the second structural phase transitions at $T_{\mathrm{S} 1}=374(2)$ and $403(2) \mathrm{K}$, respectively. Upon further cooling a second magnetic transition was found for the chromites $\mathrm{NiCr}_{2} \mathrm{O}_{4}\left[T_{\mathrm{M} 2}=24(1) \mathrm{K}\right], \mathrm{Ni}_{0.85} \mathrm{Cu}_{0.15} \mathrm{Cr}_{2} \mathrm{O}_{4}\left[T_{\mathrm{M} 2}=48(2) \mathrm{K}\right]$, and $\left(\mathrm{Ni}_{0.80} \mathrm{Cu}_{0.20} \mathrm{Cr}_{2} \mathrm{O}_{4}\right)\left[T_{\mathrm{M} 2}=67(3) \mathrm{K}\right]$. Interestingly for $\mathrm{Ni}_{0.85} \mathrm{Cu}_{0.15} \mathrm{Cr}_{2} \mathrm{O}_{4}$ and $\mathrm{Ni}_{0.80} \mathrm{Cu}_{0.20} \mathrm{Cr}_{2} \mathrm{O}_{4}$ a relatively strong magnetoelastic effect could be found for the lattice parameters $a$ and $b$ below $T_{\mathrm{M} 2}$, whereas such anomaly was not observed for the parameters $c$ (Fig. 5). Here the decrease and increase of $a$ and $b$ lead to an even stronger separation of these parameters. For the end member $\mathrm{NiCr}_{2} \mathrm{O}_{4}$ magnetic intensity was found at the position of reflection 201, whereas for the chromites $\mathrm{Ni}_{0.85} \mathrm{Cu}_{0.15} \mathrm{Cr}_{2} \mathrm{O}_{4}$ and $\mathrm{Ni}_{0.80} \mathrm{Cu}_{0.20} \mathrm{Cr}_{2} \mathrm{O}_{4}$ it was found at the position of 200, which are all forbidden in $F d d d$. However, in both cases these types of magnetic reflections can be ascribed to the onset of an additional antiferromagnetic ordering (see section D).

For $\mathrm{NiCr}_{2} \mathrm{O}_{4}$ the temperature dependence of the magnetic intensities of the reflections 110 and 201/021 is shown in Fig. 7. It can be seen that the magnetic intensity of 201/021 disappears at 24(1) $\mathrm{K}$ indicating the onset of long-range antiferromagnetic ordering. Interestingly the magnetic intensity of the 110 disappears at slightly higher temperature at $27(1) \mathrm{K}$, that is closer to the values $T_{\mathrm{M} 2}=29 \mathrm{~K}$ and $T_{\mathrm{M} 2}=31 \mathrm{~K}$ obtained earlier from susceptibility and specific-heat measurements. ${ }^{23,25}$ However, at $25.5 \mathrm{~K}$ we found for the reflection 110 a broadening and a slight displacement from the expected $2 \theta$ position (Fig. 7). It is likely that the reflection 110 contains stronger proportions of diffuse scattering, which has to be taken into account for the determination of the transition temperature $T_{\mathrm{M} 2}$. In fact an appreciable part of diffuse scattering was found earlier for $\mathrm{NiCr}_{2} \mathrm{O}_{4}$ at lower $2 \theta$ values in the 
magnetically ordered state giving an uneven background below $2 \theta=45^{\circ}$ (Fig. 7). ${ }^{35}$ Further it is important to note that no diffuse scattering was found for $\mathrm{CuCr}_{2} \mathrm{O}_{4} \cdot{ }^{35}$

In order to generate a detailed structural and magnetic phase diagram we used the Curie temperatures of $\mathrm{Ni}_{1-x} \mathrm{Cu}_{x} \mathrm{Cr}_{2} \mathrm{O}_{4}$ with $x(\mathrm{Cu})=0.40,0.60,0.80,1.00$ determined earlier from SQUID measurements. ${ }^{21}$ For some chromites $\mathrm{Ni}_{1-x} \mathrm{Cu}_{x} \mathrm{Cr}_{2} \mathrm{O}_{4}$ with $x(\mathrm{Cu}) \geq 0.30$ the transition temperatures $T_{\mathrm{S} 1}$ (from cubic to tetragonal) have been obtained from our DSC measurements. In Fig. 8 it can be seen that $T_{\mathrm{S} 1}$ almost shows a linear increase with increasing copper level reaching finally the value $846(5) \mathrm{K}$ for $\mathrm{CuCr}_{2} \mathrm{O}_{4}$. This is in good agreement with the results of Kino and Miyahara. ${ }^{17}$ The strong increase of $T_{\mathrm{S} 1}$ correlates with the degree of tetragonal distortions, which is much stronger in $\mathrm{CuCr}_{2} \mathrm{O}_{4}$ than in $\mathrm{NiCr}_{2} \mathrm{O}_{4}$. Further in Fig. 8 it can be seen that the Curie temperatures $T_{\mathrm{C}}$ of the system $\mathrm{Ni}_{1-x} \mathrm{Cu}_{x} \mathrm{Cr}_{2} \mathrm{O}_{4}$ also show an almost linear increase but much less pronounced than that of $T_{\mathrm{S} 1}$. This behavior seems to be independent of the strong stabilization of the orthorhombic distortions in the critical range $0.10 \leq x(\mathrm{Cu}) \leq$ 0.30 .

\section{Magnetic ordering in the system $\mathrm{Ni}_{1-x} \mathrm{Cu}_{x} \mathrm{Cr}_{2} \mathrm{O}_{4}$}

We now discuss the change of magnetic structures in the system $\mathrm{Ni}_{1-x} \mathrm{Cu}_{x} \mathrm{Cr}_{2} \mathrm{O}_{4}$. The magnetic structures of the end members $\mathrm{NiCr}_{2} \mathrm{O}_{4}$ and $\mathrm{CuCr}_{2} \mathrm{O}_{4}$ were investigated earlier by neutron diffraction. ${ }^{18,25,28}$ However, in these studies it was not possible to give a detailed description of the magnetic structures. Therefore, in this section we will discuss the magnetic properties of $\mathrm{NiCr}_{2} \mathrm{O}_{4}$ and $\mathrm{CuCr}_{2} \mathrm{O}_{4}$ separately.

\section{Magnetic structure of $\mathrm{NiCr}_{2} \mathrm{O}_{4}$}

The magnetic structure of $\mathrm{NiCr}_{2} \mathrm{O}_{4}$ was investigated earlier by neutron diffraction from a data set collected at $4.2 \mathrm{~K} .{ }^{28}$ In agreement with our work magnetic reflections were found to decompose into two sets, where the individual ferri- and antiferromagnetic structures were described with the propagation vectors $\boldsymbol{k}_{1}=0$ and $\boldsymbol{k}_{2}=(001)$, respectively. Below the magnetic phase transition temperature of 74(2) K magnetic intensities were only found at the position of allowed nuclear Bragg reflections, indicating the presence of a ferrimagnetic spin alignment. For $\mathrm{NiCr}_{2} \mathrm{O}_{4}$ the strongest magnetic intensity was found at the position of the reflection 111 (Figs. 4 and 6). Thus the magnetic structure can be described with the 
propagation vector $\boldsymbol{k}_{1}=0$. Below the second magnetic phase transition temperature $T_{\mathrm{M} 2}=$ 24(2) $\mathrm{K}$ a spontaneous increase of magnetic intensities were found for the reflections (110) $\mathrm{M}$ and $(201)_{\mathrm{M}} /(021)_{\mathrm{M}}$, which are forbidden in the space group $F d d d$. The temperature dependence of the magnetic intensity of the reflection pair $(201)_{M} /(021)_{M}$ is presented in Fig. 6. The reflection $(110)_{\mathrm{M}}$ and $(201)_{\mathrm{M}} /(021)_{\mathrm{M}}$ can be generated by the rule $(h k \ell)_{\mathrm{M}}=(h k \ell)_{\mathrm{N}} \pm \boldsymbol{k}_{2}$, where the propagation vector is $\boldsymbol{k}_{2}=(001)$. The loss of the $F$-centering gives a magnetic structure, wherein the moments of the atoms connected via the translation $t_{1}=( \pm 1 / 2, \pm 1 / 2,0)$ are coupled ferromagnetically, while those connected via $\boldsymbol{t}_{2}=(0, \pm 1 / 2, \pm 1 / 2)$ and $\boldsymbol{t}_{3}=( \pm 1 / 2,0, \pm 1 / 2)$ are coupled antiferromagnetically. On the other hand magnetic intensity can only be generated on the reflections $(201)_{\mathrm{M}}$ and $(021)_{\mathrm{M}}$ if additionally the $d$-glide plane symmetry is lost. Therefore, the moments of the chromium atoms connected with $\boldsymbol{t}_{4}=( \pm 1 / 4, \pm 1 / 4,0)$ are coupled antiparallel. Concerning the magnetic order of the Cr-atoms in $16 d\left[(1) \frac{1}{2}, 1 / 2,1 / 2 ;(2) 1 / 4,1 / 4,1 / 2\right.$; (3) $1 / 4,1 / 2,1 / 4$ (4) $1 / 2,1 / 4,1 / 4]$ of $F d d d$ it cannot be distinguished between the spin sequences +-+and +--+ , where one finds antiferromagnetic chains of Cr-atoms along the directions [110] and [1-10]. In agreement with the result of Bertaut and Dulac (Ref. 28) we found the chromium moments to be aligned parallel to the $c$ axis. Although, contrary to Ref. 28 our Rietveld refinements showed that the nickel moments located at $8 a\left[(1) \frac{1}{8}, 1 / 8,1 / 8 ;(2) 3 / 8,3 / 8,7 / 8\right]$ do not contribute to the antferromagnetic order. This result is compatible with the theory of Yafet and Kittel suggesting relatively weak antiferromagnetic couplings on the tetrahedral sites. ${ }^{1}$ From the Rietveld refinements of the E6 and E9 data we obtained the moment values $\mu_{z}(\mathrm{Cr})=1.15(2) \mu_{\mathrm{B}}$ and $\mu_{z}(\mathrm{Cr})=1.20(2) \mu_{\mathrm{B}}$, respectively. For the magnetic structure with $\boldsymbol{k}_{1}$ $=0$ the best fit was obtained, where the nickel and chromium moments are aligned ferrimagnetically within the $a b$-plane. The refined magnetic moments are $\mu_{x y}(\mathrm{Ni})=1.83(9) \mu_{\mathrm{B}}$ and $\mu_{x y}(\mathrm{Cr})=-0.89(7) \mu_{\mathrm{B}}(\mathrm{E} 6)$ and $\mu_{x y}(\mathrm{Ni})=1.83(9) \mu_{\mathrm{B}}$ and $\mu_{x y}(\mathrm{Cr})=-0.89(7) \mu_{\mathrm{B}}(\mathrm{E} 9)$; the total moments of the chromium atoms are $\mu_{\text {tot }}(\mathrm{Cr})=1.48(8) \mu_{\mathrm{B}}(\mathrm{E} 6)$ and $\mu_{\mathrm{tot}}(\mathrm{Cr})=1.49(9) \mu_{\mathrm{B}}$ (E9). At $36 \mathrm{~K}$ well above the second transition $T_{\mathrm{M} 2}=25(2) \mathrm{K}$ the moments in the $a b$-plane were found to be $\mu_{x y}(\mathrm{Ni})=1.69(10) \mu_{\mathrm{B}}$ and $\mu_{x y}(\mathrm{Cr})=-0.84(8) \mu_{\mathrm{B}}(\mathrm{E} 6)$. It is interesting to see that the $\mu_{x y}(\mathrm{Ni}) / \mu_{x y}(\mathrm{Cr})$ ratio seems to be stable over a wide temperature range.

\section{Magnetic structure of $\mathrm{CuCr}_{2} \mathrm{O}_{4}$}

In contrast to $\mathrm{NiCr}_{2} \mathrm{O}_{4}$ both the ferrimagnetic and the antiferromagnetic structure of $\mathrm{CuCr}_{2} \mathrm{O}_{4}$ could be described with the vector $\boldsymbol{k}=0 .{ }^{18}$ However a detailed description of the magnetic structure could not be given in Ref. 18. Therefore we have reinvestigated the 
magnetic structure of $\mathrm{CuCr}_{2} \mathrm{O}_{4}$ from neutron powder data collected at $2 \mathrm{~K}$. In order to compare the magnetic properties of $\mathrm{NiCr}_{2} \mathrm{O}_{4}$ and $\mathrm{CuCr}_{2} \mathrm{O}_{4}$ the $a$ axis of the copper chromite was set to be the pseudo-tetragonal axis. In the powder pattern (Fig. 4) it can be seen that the strongest magnetic intensity was found at the position of the allowed reflection 111 . Here it has to be mentioned that the nuclear contribution of the intensity of 111 is negligibly small. This strong intensity of the 111 again suggests the presence of ferrimagnetic ordering of the copper and chromium moments. Magnetic intensity could also be observed at the position of 200, whereas no magnetic intensity could be observed for the reflections 020 and 002 . For $\mathrm{CuCr}_{2} \mathrm{O}_{4}$ one only finds a loss of the $d$-glide plane symmetry. Magnetic intensity could be generated on the positions of 200 and 111, if the magnetic moments are aligned antiferromagnetically within the $b c$-plane. The best fit was obtained for an antiferromagnetic ordering of the Cr-atoms in $16 d\left[(1) \frac{1 / 2,1 / 2,1 / 2}{2}\right.$ (2) $1 / 4,1 / 4,1 / 2 ;$; (3) $1 / 4,1 / 2,1 / 4$ (4) $\left.1 / 2,1 / 4,1 / 4\right]$ with the spin sequence +--+ . Rietveld refinements showed that the copper moments located at $8 a[(1)$ $1 / 8,1 / 8,1 / 8 ;$; 2 ) $3 / 8,3 / 8,7 / 8]$ do not contribute to the antferromagnetic order. Due to the weak orthorhombic splitting in the $b c$ plane it was not possible to find the orientation of the $\mathrm{Cr}$ moments within the pseudotetragonal $b c$-plane ( $a^{\prime} b^{\prime}$-plane in the standard setting). A satisfactory Rietveld refinement we finally obtained from a model, where the $\mathrm{Cu}$ - and $\mathrm{Cr}$ moments are ferrimagnetically aligned parallel to the tetragonal $a$ axis ( $c$ ' axis in the standard setting). The refined ferrimagnetically coupled moments are $\mu_{x}(\mathrm{Cu})=0.85(9) \mu_{\mathrm{B}}$ and $\mu_{x}(\mathrm{Cr})=$ $-1.60(7) \mu_{\mathrm{B}}$. The magnetic moment value of the antiferromagnetic component was found to be $\mu_{y z}(\mathrm{Cr})=2.07(3) \mu_{\mathrm{B}}$ resulting finally in a total moment $\mu_{\mathrm{tot}}(\mathrm{Cr})=2.61(4) \mu_{\mathrm{B}}$.

\section{Magnetic structure of $\mathrm{Ni}_{0.85} \mathrm{Cu}_{0.15} \mathrm{Cr}_{2} \mathrm{O}_{4}$}

The magnetic structure of $\mathrm{Ni}_{0.85} \mathrm{Cu}_{0.15} \mathrm{Cr}_{2} \mathrm{O}_{4}$ has been determined from a data set collected at $2 \mathrm{~K}$. Fig. 4 shows that the observed magnetic powder pattern of $\mathrm{Ni}_{0.85} \mathrm{Cu}_{0.15} \mathrm{Cr}_{2} \mathrm{O}_{4}$ is similar to that one of the end member $\mathrm{CuCr}_{2} \mathrm{O}_{4}$, where the strongest magnetic intensities were found at the positions of the reflections 200 and 111. This already indicates the similarity of the magnetic structures of both chromites. In the present case it was possible to determine the magnetic structure of $\mathrm{Ni}_{0.85} \mathrm{Cu}_{0.15} \mathrm{Cr}_{2} \mathrm{O}_{4}$ more precisely than the structures of the end members $\mathrm{NiCr}_{2} \mathrm{O}_{4}$ and $\mathrm{CuCr}_{2} \mathrm{O}_{4}$, since the orthorhombic splitting is strongly pronounced. We were able to find systematic distributions of magnetic intensities on particular sets of reflections. This finally allowed us to determine the magnetic components of the ferri- and antiferromagnetic 
parts. The ferrimagnetic spin alignment gives magnetic contribution on nuclear Bragg reflections which are allowed in $F d d d$. The strongest magnetic intensity was found again for the reflection 111. In order to find the moment directions we focussed on the set of reflections 400, 040, and 004. Due to the similarity of the magnetic structures of $\mathrm{Ni}_{0.85} \mathrm{Cu}_{0.15} \mathrm{Cr}_{2} \mathrm{O}_{4}$ and $\mathrm{CuCr}_{2} \mathrm{O}_{4}$ we assumed a ferrimagnetic ordering within the $a b$ plane. Fig. 9 presents in detail the results of the Rietveld refinements of the neutron diffraction data of $\mathrm{Ni}_{0.85} \mathrm{Cu}_{0.15} \mathrm{Cr}_{2} \mathrm{O}_{4}$ collected at $2 \mathrm{~K}$. Here it can be seen that only the reflections 040 and 004 contain magnetic intensity. The absence of magnetic intensity on the 400 already indicates that the moments are aligned parallel to the $a$ axis. Finally, a satisfactory fit was obtained for the model, where the moments are aligned parallel to the $a$ axis. In a similar way we were able to determine the moment direction of the antiferromagnetically coupled chromium atoms from the reflections 024, 204, 042, 240, 402, and 420 (listed with increasing 20). But first we already can exclude a spin alignment along the $a$ axis, since the strongest magnetic intensity of this set was found on the 200. For the other six reflections listed above magnetic intensity could only be generated on the reflections 204 and 024 assuming an antiferromagnetic ordering along the $b$ and $c$ axes. However in Fig. 9 it can be seen that the better fit was obtained, when the $\mathrm{Cr}$ moments are aligned parallel to the $c$ axis. Therefore it can be concluded that a noncollinear ordering in $\mathrm{Ni}_{0.85} \mathrm{Cu}_{0.15} \mathrm{Cr}_{2} \mathrm{O}_{4}$ is found to be in the $a c$ plane.

\section{CONCLUSIONS}

Fig. 8(a) summarizes the structural and magnetic phase diagram of the system $\mathrm{Ni}_{1-x} \mathrm{Cu}_{x} \mathrm{Cr}_{2} \mathrm{O}_{4}$ showing the evolution of the structural and magnetic phase transition temperatures. A change from cubic to tetragonal symmetry occurs in the range $317 \mathrm{~K} \leq T_{\mathrm{S} 1} \leq$ $846 \mathrm{~K}$ due to the onset of Jahn-Teller activities and gives rise to orbital ordering. The crystal structure of the end members $\mathrm{NiCr}_{2} \mathrm{O}_{4}$ and $\mathrm{CuCr}_{2} \mathrm{O}_{4}$ changes to a lower orthorhombic structure with the space group $F d d d$ at the Curie temperatures $T_{\mathrm{C}}=74 \mathrm{~K}$ and $T_{\mathrm{C}}=135 \mathrm{~K}$, respectively, due to magnetoelastic effects. In the case of $\mathrm{CuCr}_{2} \mathrm{O}_{4}$ the orthorhombic splitting was found to be less pronounced possibly due to the dominating tetragonal distortion. Figs. 2 and 8 (c) show the variation of the lattice parameters in the solid solution series $\mathrm{Ni}_{1-x} \mathrm{Cu}_{x} \mathrm{Cr}_{2} \mathrm{O}_{4}$ at $2 \mathrm{~K}$ and at room temperature, where one finds a strong orthorhombic splitting in the range $0.10<x(\mathrm{Cu})<0.30$. In this work it could be shown that the presence of strong orthorhombic distortions can be ascribed to the fact that an elongation of the $\mathrm{NiO}_{4}$ tetrahedra occurs along 
the $c$ axis $(a=b<c)$, whereas a flattening of the $\mathrm{CuO}_{4}$ tetrahedra occurs along $a(a<b=c)$. Therefore a transition into the other tetragonal state requires the presence of an intermediate orthorhombic phase. Fig. 8(a) shows that the orthorhombic structure of $\mathrm{Ni}_{0.85} \mathrm{Cu}_{0.15} \mathrm{Cr}_{2} \mathrm{O}_{4}$ is optimally stabilized almost up to the transition temperature $T_{\mathrm{S} 1}$. If the Jahn-Teller activities on the $A$ site were along the same crystallographic direction for $A=\mathrm{Ni}$ and $\mathrm{Cu}$ then electronic compensation would be expected at this doping, resulting in a transition back to the highsymmetric cubic phase.

In section $\mathrm{C}$ we gave a detailed description of the magnetic structures of the end members $\mathrm{NiCr}_{2} \mathrm{O}_{4}$ and $\mathrm{CuCr}_{2} \mathrm{O}_{4}$. From our Rietveld refinements it was not possible to determine the direction of the magnetic component in the pseudo-tetragonal basis plane. The ferrimagnetic mode of $\mathrm{NiCr}_{2} \mathrm{O}_{4}$ has a component in the $a b$ plane $\left[\mu_{x y}(\mathrm{Ni})=-\mu_{x y}(\mathrm{Cr})\right]$, while the antiferromagnetic mode of $\mathrm{CuCr}_{2} \mathrm{O}_{4}$ has a component in the $b c$ plane $\left[\mu_{y z}(\mathrm{Cr})\right]$. Conversely we were able to determine precisely the magnetic structure of $\mathrm{Ni}_{0.85} \mathrm{Cu}_{0.15} \mathrm{Cr}_{2} \mathrm{O}_{4}$ due to the presence of strong orthorhombic distortions resulting in proper peak splitting. We clearly found that the ferrimagnetically coupled moments of the $\mathrm{Ni} / \mathrm{Cu}$ and $\mathrm{Cr}$ atoms are aligned parallel to the $a$ axis, while the antiferromagnetically coupled $\mathrm{Cr}$ moments are aligned parallel to the $c$ axis. The same type of magnetic ordering was found for the chromite $\mathrm{Ni}_{0.80} \mathrm{Cu}_{0.20} \mathrm{Cr}_{2} \mathrm{O}_{4}$ containing a slightly higher $\mathrm{Cu}$ content. Further in Fig. 10 it can be seen that the magnetic structures of both chromites $\mathrm{Ni}_{0.85} \mathrm{Cu}_{0.15} \mathrm{Cr}_{2} \mathrm{O}_{4}$ and $\mathrm{CuCr}_{2} \mathrm{O}_{4}$ look quite the same assuming a magnetic ordering in the $a c$ plane. This lead us to the adoption of these conclusions in giving a general model of magnetic ordering in the system $\mathrm{Ni}_{1-x} \mathrm{Cu}_{x} \mathrm{Cr}_{2} \mathrm{O}_{4}$, and where the ferrimagnetically coupled moments of the $\mathrm{Ni} / \mathrm{Cu}$ and $\mathrm{Cr}$ atoms are aligned parallel to the $a$ axis, while the antiferromagnetically coupled $\mathrm{Cr}$ moments are aligned parallel to the $c$ axis. Further structural considerations support this statement. Concerning the lattice parameters of the system $\mathrm{Ni}_{1-x} \mathrm{Cu}_{x} \mathrm{Cr}_{2} \mathrm{O}_{4}$ the condition $a<b<c$ could be maintained continuously throughout the whole composition range. Table I shows that the change of the bond lengths $d(A-\mathrm{O})$ and $d(\mathrm{Cr}-\mathrm{O})$ in this system is negligible. On the other hand the strongest changes were found for the bond angles $\angle(\mathrm{O}-A-\mathrm{O})$ of the $A \mathrm{O}_{4}$ tetrahedra due to the strong change of the Jahn-Teller activities, but interestingly one also finds a general trend $\angle_{a}(\mathrm{O}-A$ $\mathrm{O})>\angle{ }_{b}(\mathrm{O}-A-\mathrm{O})>\angle_{c}(\mathrm{O}-A-\mathrm{O})$. As already mentioned in section $\mathrm{B}$ the bisectors of $\angle{ }_{a}(\mathrm{O}-A-$ $\mathrm{O}), \angle_{b}(\mathrm{O}-A-\mathrm{O})$, and $\angle_{c}(\mathrm{O}-A-\mathrm{O})$ correspond to the $a, b$, and $c$ axes, respectively. For $\mathrm{Ni}_{0.85} \mathrm{Cu}_{0.15} \mathrm{Cr}_{2} \mathrm{O}_{4}$ we clearly found that the magnetic moments of the $A$ atoms ( $\mathrm{Ni}$ and $\mathrm{Cu}$ ) are aligned parallel to the $a$ axis, or parallel to the bisector of that bond angle, whichever is the largest. Due to the fact that this trend is found in the whole system $\mathrm{Ni}_{1-x} \mathrm{Cu}_{x} \mathrm{Cr}_{2} \mathrm{O}_{4}$ it can be 
assumed that the ferrimagnetically coupled $A$ and $\mathrm{Cr}$ moments are always aligned parallel to a. Concerning the data analysis of $\mathrm{CuCr}_{2} \mathrm{O}_{4}$ given above it was not possible to determine the orientation of the antiferromagnetically coupled $\mathrm{Cr}$ moments in the $b c$ plane. Here again structural considerations can give a clearer statement. In $\mathrm{NiCr}_{2} \mathrm{O}_{4}, \mathrm{Ni}_{0.85} \mathrm{Cu}_{0.15} \mathrm{Cr}_{2} \mathrm{O}_{4}$ and $\mathrm{Ni}_{0.80} \mathrm{Cu}_{0.20} \mathrm{Cr}_{2} \mathrm{O}_{4}$ the $\mathrm{Cr}$ moments of the antiferromagnetic mode were found to be aligned parallel to the $c$ axis, which is always the largest of the three axes in the system $\mathrm{Ni}_{1-x} \mathrm{Cu}_{x} \mathrm{Cr}_{2} \mathrm{O}_{4}$. Therefore it likely that the antiferromagnetic component of $\mathrm{CuCr}_{2} \mathrm{O}_{4}$ is also aligned parallel to $c$.

For the Ni-rich chromites $\mathrm{NiCr}_{2} \mathrm{O}_{4}, \mathrm{Ni}_{0.85} \mathrm{Cu}_{0.15} \mathrm{Cr}_{2} \mathrm{O}_{4}, \mathrm{Ni}_{0.80} \mathrm{Cu}_{0.20} \mathrm{Cr}_{2} \mathrm{O}_{4}$ a second magnetic transition was found at $T_{\mathrm{M} 2}$, where one finds the onset of antiferromagnetic ordering of the chromium atoms. In Fig. $8(\mathrm{a})$ it can be seen that $T_{\mathrm{M} 2}$ strongly increases with increasing $\mathrm{Cu}$ content. Up to a level $x(\mathrm{Cu}) \sim 0.4$ the ferri- and antiferromagnetic transitions (at $T_{\mathrm{C}}$ and $\left.T_{\mathrm{M} 2}\right)$ are found to be merged into one other. This shows that frustration effects are more and more reduced with increasing $\mathrm{Cu}$ content, leading to a better stabilization of the antiferromagnetic ordering of the chromium atoms. A division into two sets of spin structures was suggested by Yafet and Kittel already in the 1950s. ${ }^{1}$ In agreement with the results of Bertaut and Dulac (Ref. 28) we found the antiferromagnetically coupled Cr moments to be aligned parallel to the $c$ axis in $\mathrm{NiCr}_{2} \mathrm{O}_{4}$. This has been also observed for $\mathrm{Ni}_{0.85} \mathrm{Cu}_{0.15} \mathrm{Cr}_{2} \mathrm{O}_{4}$, despite the fact that the propagation vector $\boldsymbol{k}_{2}=(001)$ of the antiferromagnetic mode of $\mathrm{NiCr}_{2} \mathrm{O}_{4}$ is different from $\boldsymbol{k}=0$ found for chromites with $x(\mathrm{Cu}) \geq 0.15$. In Fig. 10 it can be seen that $\mathrm{Ni}_{0.85} \mathrm{Cu}_{0.15} \mathrm{Cr}_{2} \mathrm{O}_{4}$ and $\mathrm{CuCr}_{2} \mathrm{O}_{4}$ show a ferromagnetic coupling $(++++)$ along the $c$ direction, while in $\mathrm{NiCr}_{2} \mathrm{O}_{4}$ it is antiferromagnetic with the sequence ++-- . Possibly an elongation of $c$ and a contraction of $b$ cause in $\mathrm{NiCr}_{2} \mathrm{O}_{4}$ a change of exchange interactions.

In this paragraph we discuss the evolution of the total magnetic moments $\mu_{\mathrm{tot}}$ of the metal atoms and their components $\mu_{x}$ and $\mu_{z}$, which is shown in Fig. 8(b). First we focus on the magnetic moments of the $A$ atoms ( $\mathrm{Ni}$ and $\mathrm{Cu}$ ) with a moment direction parallel to the $a$ axis. For the end members $\mathrm{NiCr}_{2} \mathrm{O}_{4}$ and $\mathrm{CuCr}_{2} \mathrm{O}_{4}$ the moments reach the values $\mu_{x}(\mathrm{Ni})=1.83(7)$ $\mu_{\mathrm{B}}$ and $\mu_{x}(\mathrm{Cu})=0.85(9) \mu_{\mathrm{B}}$, respectively. Here the Ni moments $\left(\mathrm{Ni}^{2+}, 3 d^{8}\right)$ reach about $92 \%$ of the theoretical value $\mu_{\mathrm{S}}\left(\mathrm{Ni}^{2+}\right)=2 \cdot \mathrm{S} \mu_{\mathrm{B}}=2 \mu_{\mathrm{B}}$; the $\mathrm{Cu}$ moments about $85 \%$ of the value $\mu_{\mathrm{S}}\left(\mathrm{Cu}^{2+}\right)=2 \cdot \mathrm{S} \mu_{\mathrm{B}}=1 \mu_{\mathrm{B}}$. Our refinements could not evidence any significant antiferromagnetic component of $\mathrm{Ni} / \mathrm{Cu}$ along the $c$ axis, which is in contrast to the results given in Ref. 28. Fig. 8(b) shows that the moment on the $A$ site is slightly stabilized with increasing $\mathrm{Cu}$ content up to $x(\mathrm{Cu}) \sim 0.20$ caused by a reduction of frustration in the strongly 
distorted orthorhombic structure. The ordering of the $\mathrm{Cr}$ moments is of particular interest because of their location on a pyrochlore lattice which is one of the most geometrically frustrated lattices. Long-range antiferromagnetic order is highly suppressed on an ideal pyrochlore lattice, however distortions from ideal pyrochlore symmetry would be expected to partially or completely lift the frustration. The structural refinements reveal significant distortion from ideal pyrochlore symmetry in $\mathrm{Ni}_{1-x} \mathrm{Cu}_{x} \mathrm{Cr}_{2} \mathrm{O}_{4}$ which is greater in $\mathrm{CuCr}_{2} \mathrm{O}_{4}$ than $\mathrm{NiCr}_{2} \mathrm{O}_{4}$. In the ferrimagnetic structure the Cr moments $\mu_{x}(\mathrm{Cr})=-0.89(7) \mu_{\mathrm{B}}$ and $\mu_{x}(\mathrm{Cr})=$ $-1.60(7) \mu_{\mathrm{B}}$ of the end members $\mathrm{NiCr}_{2} \mathrm{O}_{4}$ and $\mathrm{CuCr}_{2} \mathrm{O}_{4}$ were found to be very different. The same tendency was found for the antiferromagnetically coupled $z$ components $\mu_{z}(\mathrm{Cr})=$ $1.20(2) \mu_{\mathrm{B}}$ to $\mu_{z}(\mathrm{Cr})=-2.07(7) \mu_{\mathrm{B}}$. The total moment value $\mu_{\mathrm{tot}}(\mathrm{Cr})=-2.61(4) \mu_{\mathrm{B}}$ of $\mathrm{CuCr}_{2} \mathrm{O}_{4}$ reaches about $87 \%$ of the theoretical value $\mu_{\mathrm{S}}\left(\mathrm{Cr}^{2+}\right)=2 \cdot \mathrm{S} \mu_{\mathrm{B}}=3 \mu_{\mathrm{B}}$. Due to stronger frustration effects caused by smaller distortions in $\mathrm{NiCr}_{2} \mathrm{O}_{4}$ the $\mathrm{Cr}$ moments only reach a moment value of $\mu_{\mathrm{tot}}(\mathrm{Cr})=1.49(4) \mu_{\mathrm{B}}$. This value is even smaller than the chromium moments in $A \mathrm{Cr}_{2} \mathrm{O}_{4}(A=\mathrm{Mg}, \mathrm{Zn}, \mathrm{Hg})$ which vary between 1.7 and $2.0 \mu_{\mathrm{B}} .{ }^{10}$ Further it can be seen in Fig. 8(b) that $\mu_{x}(\mathrm{Cr})$ shows a strong increase from $x(\mathrm{Cu})=0.80$ to 1.00 . It is also likely that the antiferromagnetic $x$-component is preferably reduced by local strain effects based on competing Jahn-Teller effects. Due to the spin reduction the chromium moments were found to be partially in a disordered state, which coexists with magnetic long-range order below $T_{\mathrm{N}}$. Recently the disordered state was described as a new class of a spin-liquidlike state caused by geometrical frustration. ${ }^{10}$ The presence of diffuse scattering in the lowtemperature neutron powder patterns of $\mathrm{NiCr}_{2} \mathrm{O}_{4}$ also indicates short-range order of the chromium moments. A similar behavior was found for $\mathrm{MnCr}_{2} \mathrm{O}_{4}$ and $\mathrm{CoCr}_{2} \mathrm{O}_{4}$, where only the spiral component exhibits short-range order and local instabilities, which can be described as a reentrant-spin-glass-like behavior. ${ }^{12}$ In the system $\mathrm{Ni}_{1-x} \mathrm{Cu}_{x} \mathrm{Cr}_{2} \mathrm{O}_{4}$ especially the antiferromagnetically coupled chromium moments show a spontaneous increase in the range $0.10<x(\mathrm{Cu})<0.20$ (Fig. 8), where strong orthorhombic distortions cause a considerable reduction of frustration resulting possibly in an enhancement of the long-range order. Further studies will be necessary to give a more detailed description of these rather complex magnetic states.

$\mathrm{Ni}_{1-x} \mathrm{Cu}_{x} \mathrm{Cr}_{2} \mathrm{O}_{4}$ can be compared to the related compounds $A B_{2} \mathrm{O}_{4}$ where the $A$-site ions are non-magnetic and the pyrochlore lattice is formed of $B=\mathrm{Cr}^{3+}, \mathrm{V}^{3+}$. In the case of $\mathrm{V}^{3+}$, orbital degrees of freedom within the $B$ sublattice drive a Jahn-Teller distortion of the $\mathrm{VO}_{6}$ octahedra which also partially lifts the magnetic frustration; long-range magnetic order then occurs at a 
lower temperature. In contrast for $B=\mathrm{Cr}^{3+}$ and $A$ non-magnetic, there are no orbital degrees of freedom and the structural transition which coincides with the transition to long-range magnetic order is driven by the need to reduce the frustration via magneto-elastic coupling. In $\mathrm{Ni}_{1-x} \mathrm{Cu}_{x} \mathrm{Cr}_{2} \mathrm{O}_{4}$ where both the $A$-site and $B$-site ions are magnetic and furthermore the $A$ site (rather than the $B$ site) is Jahn-Teller active the transitions are much more complex as shown in this paper. The first structural transition is driven by the Jahn-Teller effect on the A site but does not relieve the magnetic frustration sufficiently to allow the long-range magnetic order at low temperatures except for $0.10<x<0.20$ where competing Jahn-Teller distortions produce additional symmetry lowering. Elsewhere the transition to long-range magnetic order is accompanied by a second structural phase transition which as for the $A \mathrm{Cr}_{2} \mathrm{O}_{4}$ (with $A$ nonmagnetic) is driven by magneto-elastic coupling.

\section{ACKNOWLEDGEMENT}

We thank C. Leistner for the technical assistance to carry out the DSC measurements. We also thank R. Feyerherm and W. Jauch for fruitful discussions.

\section{References}

${ }^{1}$ Y. Yafet, and C. Kittel, Phys. Rev. 87, 290 (1952).

${ }^{2}$ P. W. Anderson, Phys. Rev. 102, 1008 (1956).

${ }^{3}$ P. G. Radaelli, New J. Phys. 7, 53 (2005).

${ }^{4}$ M. Reehuis, A. Krimmel, N. Büttgen, A. Loidl, A. Prokofiev, Eur. Phys. J. B 35, 311 (2003).

${ }^{5}$ E. M. Wheeler, B. Lake, A. T. M. N. Islam, M. Reehuis, P. Steffens, T. Guidi, A. H. Hill, Phys. Rev. B 82, 140406(R) (2010).

${ }^{6}$ S.-H. Lee, C. Broholm, T. H. Kim, W. Ratcliff, and S.-W. Cheong, Phys. Rev. Lett. 84, 3718 (2000).

${ }^{7}$ S. Ji, S.-H. Lee, C. Broholm, T. Y. Koo, W. Ratcliff, S.-W. Cheong, and P. Zschack, Phys. Rev. Lett. 103, 037201 (2009).

${ }^{8}$ M. C. Kemei, P. T. Barton, S. L. Moffit, M. W. Gaultois, J. A. Kurzman, R. Seshadri, M. R. Suchomel, and Y.-I. Kim, J. Phys.: Condens. Matter 25, 326001 (2013). 
${ }^{9}$ H. Ueda, H. Mitamura, T. Gota, and Y. Ueda, Phys. Rev. B 73, 094415 (2006).

${ }^{10}$ K. Tomiyasu, H. Ueda, M. Matsuda, M. Yokoyama, K. Iwasa, and K. Yamada, Phys. Rev. B 84, 035415 (2011).

${ }^{11}$ N. Menyuk, K. Dwight, and A. Wold, J. Phys. (Paris) 25, 528 (1964).

${ }^{12}$ K. Tomiyasu, J. Fukunaga, H. Suzuki, Phys. Rev. B 70, 214434 (2004).

${ }^{13}$ Y. Yamasaki, S. Miyasaka, Y. Kaneko, J.-P. He, T. Arima, and Y. Tokura, Phys. Rev. Lett. 96, 207204 (2006).

${ }^{14}$ J. D. Dunitz, and L. E. Orgel, J. Phys. Chem. Solids 3, 20 (1957).

15 J. B. Goodenough, J. Phys. Soc. Jpn. 17, Suppl. B-I, 185 (1962).

${ }^{16}$ A. Wold, R. J. Arnott, E. Whipple, and J. B. Goodenough, J. Appl. Phys. 34, 1085 (1963).

${ }^{17}$ Y. Kino, and S. Miyahara, J. Phys. Soc. Jpn. 21, 2732 (1966).

${ }^{18}$ E. Prince, Acta. Cryst. 10, 554 (1957).

${ }^{19}$ W. A. Dollase, H. St. C. O’Neill, Acta Cryst. C 53, 657 (1997).

${ }^{20}$ O. Crottaz, F. Kubel, and H. Schmid, J. Mater. Chem. 7, 143 (1997).

${ }^{21}$ M. Tovar, R. Torabi, C. Welker, F. Fleischer, Physica B 385-386, 196 (2006).

${ }^{22}$ M. R. Suchomel, D. P. Shoemaker, L. Ribaud, M. C. Kemei, R. Seshadri, Phys. Rev. B 86 054406 (2012).

${ }^{23}$ S. Klemme, and J. C. van Miltenburg, Phys. Chem. Minerals 29, 663 (2002).

${ }^{24}$ Z.-G. Yé, O. Crottaz, F. Vaudano, F. Kubel, P. Tissot, and H. Schmid, Ferroelectr. Lett. 162, 103 (1994).

${ }^{25}$ K. Tomiyasu, and I. Kagomiya, J. Phys. Soc. Jpn. 73, 2539 (2004).

${ }^{26}$ T. T. Gurgel, M. A. Buzinaro, and N. O. Moreno, J. J. Supercond. Nov. Magn. 26, 2557 (2013).

${ }^{27}$ K. Ohgushi, Y. Okimoto, T. Ogasawara, S. Miyasaka, and Y. Tokura, J. Phys. Soc. Jpn. 77, 034713 (2008).

${ }^{28}$ E. F. Bertaut, and J. Dulac, Acta Cryst. A 28, 580 (1972).

${ }^{29}$ D. M. Többens, N. Stüßer, K. Knorr, H. M. Mayer, and G. Lampert, Materials Science Forum 378-381, 288 (2001).

${ }^{30}$ J. Rodríguez-Carvajal, FullProf: a Program for Rietveld Refinement and Pattern Matching Analysis, Abstract of the Satellite Meeting on Powder Diffraction of the XV Congress of the IUCr, Toulouse, 127 (1990).

${ }^{31}$ V. F. Sears, in: International Tables for Crystallography, Vol. C, Ed. A. J. C. Wilson (Kluwer Academic Publishers, Dordrecht/Boston/London), 383 (1995). 
${ }^{32}$ P. J. Brown, in: International Tables for Crystallography, Vol. C, Ed. A. J. C. Wilson (Kluwer Academic Publishers, Dordrecht/Boston/London), 391 (1995).

${ }^{33}$ M. Kataoka, and J. Kanamori, J. Phys. Soc. Jpn. 32, 113 (1972).

34 International Tables for Crystallography, Vol. A, Ed. T. Hahn (Kluwer Academic Publishers, Dordrecht/Boston/London), 312 (1995).

${ }^{35}$ K. Tomiyasu, H. Hiraka, K. Ohoyama, and K. Yamada, J. Phys. Soc. Jpn. 77, 124703 (2008). 
TABLE I. Results of the structure refinements of several samples of the system $\mathrm{Ni}_{1-x} \mathrm{Cu}_{x} \mathrm{Cr}_{2} \mathrm{O}_{4}$. For the data collected at $2 \mathrm{~K}$ their crystal structures were refined in the orthorhombic space group $F d d d$. Additionally, the parameters are also listed for the samples with $x(\mathrm{Cu})=0.15$ and 0.20 obtained from data sets collected at 50 and $80 \mathrm{~K}$, respectively. The interatomic distances (in $\AA$ ), and the bond angles (in deg) in the $A \mathrm{O}_{4}$-tetrahedron $(A=\mathrm{Ni}$, $\mathrm{Cu})$ and the $\mathrm{CrO}_{6}$-octahedron are also given. For samples with $x(\mathrm{Cu})>0.40$ no orthorhombic splitting could be observed in our neutron powder diffraction study. Therefore, the lattice parameters $b$ and $c$, as well as the positional parameters $y(\mathrm{O})$ and $z(\mathrm{O})$ were constrained to be equal during the refinements. In the lower part of the Table the magnetic moments of the $A$ ( $A$ $=\mathrm{Ni}, \mathrm{Cu})$ and $\mathrm{Cr}$ atoms are given.

\begin{tabular}{|c|c|c|c|c|c|c|c|c|c|c|}
\hline " $x(\mathrm{Cu})$ & 0.00 & 0.15 & 0.15 & 0.20 & "0.20 & 0.30 & 0.40 & "0.60 & 0.80 & 1.00 \\
\hline$T[\mathrm{~K}]$ & 2 & 2 & 50 & 2 & 80 & 2 & 2 & 2 & 2 & 2 \\
\hline$a[\AA]$ & $8.1661(2)$ & $8.0565(3)$ & $8.0886(3)$ & $8.0127(2)$ & $8.0557(2)$ & $7.9664(2)$ & $7.9248(2)$ & $7.8495(2)$ & $7.7738(3)$ & $7.7136(2)^{\mathrm{a}}$ \\
\hline$b[\AA]$ & $8.1794(2)$ & $8.3129(3)$ & $8.2900(3)$ & $8.3640(2)$ & $8.3339(2)$ & $8.4491(2)$ & $8.4740(3)$ & $8.5050(2)$ & $8.5241(2)$ & $8.5368(2)^{\mathrm{a}}$ \\
\hline$c[\AA]$ & $8.5623(2)$ & $8.5384(3)$ & $8.5312(4)$ & $8.5187(2)$ & $8.5116(2)$ & $8.4810(2)$ & $8.4836(3)$ & 8.5050 & 8.5241 & $8.5368^{a}$ \\
\hline$V\left[\AA^{3}\right]$ & $571.91(2)$ & $571.91(2)$ & $571.91(2)$ & $570.91(2)$ & $571.43(2)$ & $570.84(2)$ & $569.72(3)$ & $567.79(3)$ & $564.85(3)$ & $562.14(3)$ \\
\hline$x(\mathrm{O})$ & $0.2572(3)$ & $0.2557(2)$ & $0.2560(2)$ & $0.2536(1)$ & $0.2549(1)$ & $0.2520(1)$ & $0.2514(1)$ & $0.2486(1)$ & $0.2463(2)$ & $0.2453(2)$ \\
\hline$y(\mathrm{O})$ & $0.2580(3)$ & $0.2615(2)$ & $0.2609(2)$ & $0.2629(1)$ & $0.2621(1)$ & $0.2654(1)$ & $0.2659(1)$ & $0.2671(1)$ & $0.2676(1)$ & $0.2680(1)$ \\
\hline$z(\mathrm{O})$ & $0.2681(1)$ & $0.2676(2)$ & $0.2673(2)$ & $0.2665(1)$ & $0.2666(1)$ & $0.2660(2)$ & 0.2659 & 0.2671 & 0.2676 & 0.2680 \\
\hline$R_{\mathrm{N}}(F)$ & 0.016 & 0.018 & 0.023 & 0.017 & 0.014 & 0.014 & 0.014 & 0.019 & 0.017 & 0.023 \\
\hline$d(A-\mathrm{O})$ & $1.9619(20)$ & $1.9693(15)$ & $1.9663(17)$ & $1.9610(9)$ & $1.9625(9)$ & $1.9646(13)$ & $1.9643(8)$ & $1.9652(9)$ & $1.9608(13)$ & $1.9605(9)$ \\
\hline$\angle_{a}(\mathrm{O}-A-\mathrm{O})$ & $113.26(10)$ & $115.34(6)$ & $114.77(7)$ & $116.60(4)$ & $115.57(4)$ & $118.03(5)$ & $118.67(4)$ & $120.82(5)$ & $122.54(7)$ & $123.50(5)$ \\
\hline$\angle_{b}(\mathrm{O}-A-\mathrm{O})$ & $112.63(10)$ & $109.64(6)$ & $110.08(6)$ & $107.94(4)$ & $108.79(4)$ & $105.74(6)$ & $105.13(3)$ & 104.11(3) & $103.36(5)$ & $102.95(4)$ \\
\hline$\angle_{c}(\mathrm{O}-A-\mathrm{O})$ & $102.74(7)$ & 103.64(6) & $103.75(7)$ & $104.14(4)$ & $104.26(4)$ & $105.00(6)$ & $105.03(3)$ & $104.11(3)$ & $103.36(5)$ & $102.95(4)$ \\
\hline$d_{a}(\mathrm{Cr}-\mathrm{O})^{\mathrm{b}}$ & $1.9902(25)$ & $1.9760(15)$ & $1.9810(15)$ & $1.9822(10)$ & $1.9823(10)$ & $1.9849(10)$ & $1.9792(10)$ & $1.9839(12)$ & $1.9840(17)$ & $1.9766(12)$ \\
\hline$d_{b}(\mathrm{Cr}-\mathrm{O})^{\mathrm{b}}$ & $1.9860(25)$ & $1.9890(15)$ & $1.9881(17)$ & $1.9882(9)$ & $1.9880(9)$ & $1.9872(14)$ & $1.9883(8)$ & $1.9863(8)$ & $1.9866(12)$ & $1.9865(8)$ \\
\hline$d_{c}(\mathrm{Cr}-\mathrm{O})^{\mathrm{b}}$ & $1.9880(10)$ & $1.9875(15)$ & $1.9878(18)$ & $1.9922(9)$ & $1.9900(9)$ & $1.9887(14)$ & $1.9905(8)$ & $1.9863(8)$ & $1.9866(12)$ & $1.9865(8)$ \\
\hline$\angle_{1}(\mathrm{O}-\mathrm{Cr}-\mathrm{O})$ & $83.59(8)$ & $82.89(6)$ & $83.10(7)$ & $82.83(4)$ & $83.01(4)$ & $82.33(6)$ & $82.22(3)$ & $81.61(3)$ & $81.31(5)$ & $81.09(3)$ \\
\hline$\angle_{2}(\mathrm{O}-\mathrm{Cr}-\mathrm{O})$ & $83.80(8)$ & $84.19(6)$ & $84.21(7)$ & $84.94(4)$ & $84.65(4)$ & $85.39(5)$ & $85.51(4)$ & $85.82(4)$ & $86.18(6)$ & $86.24(4)$ \\
\hline$\angle{ }_{3}(\mathrm{O}-\mathrm{Cr}-\mathrm{O})$ & $86.08(10)$ & $85.58(6)$ & $85.67(7)$ & $85.76(4)$ & $85.67(4)$ & $85.54(5)$ & $85.52(4)$ & $85.82(4)$ & $86.18(6)$ & $86.24(4)$ \\
\hline$\angle{ }_{a}(A-\mathrm{O}-\mathrm{Cr})^{\mathrm{c}}$ & 118.77(10) & $117.25(7)$ & $117.69(9)$ & $116.60(5)$ & $117.24(5)$ & $115.55(7)$ & $115.13(4)$ & $113.64(4)$ & $112.58(6)$ & $111.93(4)$ \\
\hline$\angle_{b}(A-\mathrm{O}-\mathrm{Cr})^{\mathrm{c}}$ & 119.21(10) & $121.02(8)$ & $120.81(9)$ & $122.38(5)$ & $121.78(5)$ & $123.82(7)$ & $124.22(4)$ & $124.82(5)$ & $125.34(7)$ & $125.54(5)$ \\
\hline$\angle_{c}(A-\mathrm{O}-\mathrm{Cr})^{\mathrm{c}}$ & $126.10(12)$ & $125.25(8)$ & $125.26(9)$ & $125.04(5)$ & $124.96(5)$ & $124.33(7)$ & $124.27(4)$ & $124.82(5)$ & $125.34(7)$ & $125.54(5)$ \\
\hline$\mu_{x}(A)\left[\mu_{\mathrm{B}}\right]$ & $1.83(9)$ & $1.88(15)$ & $1.35(21)$ & $1.94(7)$ & $1.28(9)^{\mathrm{d}}$ & $1.82(12)$ & $1.58(14)$ & $1.23(18)$ & $0.90(20)$ & $0.85(9)$ \\
\hline$\mu_{x}(\mathrm{Cr})\left[\mu_{\mathrm{B}}\right]$ & $0.89(7)$ & $1.23(10)$ & $1.11(15)$ & $1.10(5)$ & $0.92(7)^{\mathrm{d}}$ & $0.99(9)$ & $1.00(10)$ & $1.13(13)$ & $0.99(14)$ & $1.60(7)$ \\
\hline$\mu_{z}(\mathrm{Cr})\left[\mu_{\mathrm{B}}\right]$ & $1.20(2)$ & $1.83(4)$ & - & $2.12(2)$ & - & $2.09(3)$ & $2.13(3)$ & $2.04(3)$ & $2.15(3)$ & $2.07(3)$ \\
\hline$\mu_{\mathrm{tot}}(\mathrm{Cr})\left[\mu_{\mathrm{B}}\right]$ & $1.49(4)$ & $2.20(7)$ & $1.11(15)$ & $2.39(3)$ & $0.92(7)^{\mathrm{d}}$ & $2.31(5)$ & $2.35(5)$ & $2.33(7)$ & $2.36(6)$ & $2.61(4)$ \\
\hline$R_{\mathrm{M}}($ Int. $)$ & $0.049 / 0.150$ & 0.080 & 0.042 & 0.028 & 0.102 & 0.071 & 0.058 & 0.058 & 0.030 & 0.041 \\
\hline
\end{tabular}

\footnotetext{
a compared to $a=7.71271(2) \AA, b=8.53611(2) \AA, c=8.54357(2) \AA$ of Ref. 22.

${ }^{\mathrm{b}}$ compared to $\angle{ }_{a}(\mathrm{O}-A-\mathrm{O})=123.62(4)^{\circ}, \angle_{b}(\mathrm{O}-A-\mathrm{O})=102.93(7)^{\circ}, \angle_{c}(\mathrm{O}-A-\mathrm{O})=102.86(7)^{\circ}$ calculated from the data of Ref. 22.

${ }^{\mathrm{c}}$ for $d_{a}$ and $\angle{ }_{a}(A-\mathrm{O}-\mathrm{Cr})\left(d_{b}\right.$ and $\angle_{b}, d_{c}$ and $\left.\angle_{c}\right) \mathrm{Cr}-\mathrm{O}$ bond is almost parallel to the orthorhombic $a(b, c)$ axis.

d magnetic moments obtained at $70 \mathrm{~K}$.
} 

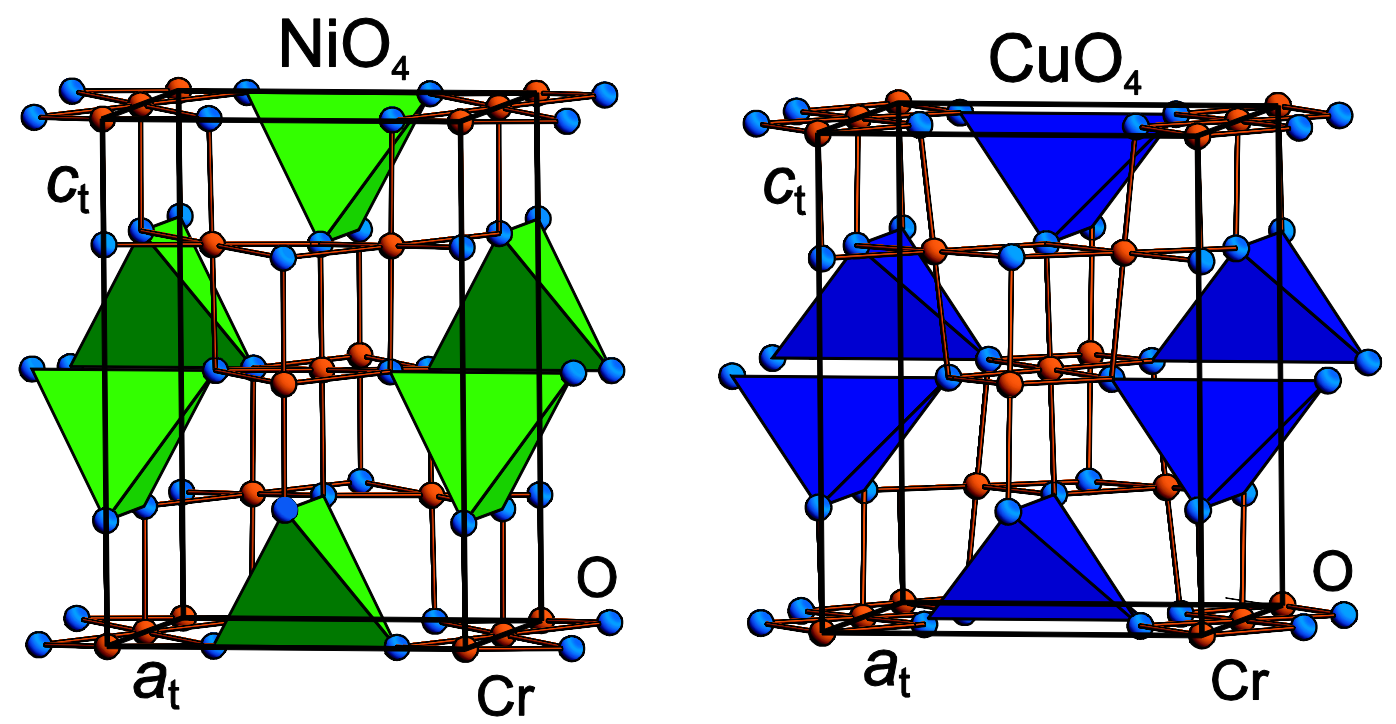

Fig. 1. (Color online) Tetragonal crystal structure of $\mathrm{NiCr}_{2} \mathrm{O}_{4}$ and $\mathrm{CuCr}_{2} \mathrm{O}_{4}$ (in $\mathrm{I}_{1} /$ amd ) A strong Jahn-Teller activity results in an elongation of the $\mathrm{NiO}_{4}$-tetraedra and a flattening of the $\mathrm{CuO}_{4}$-tetraedra along the tetragonal $c$-axis.
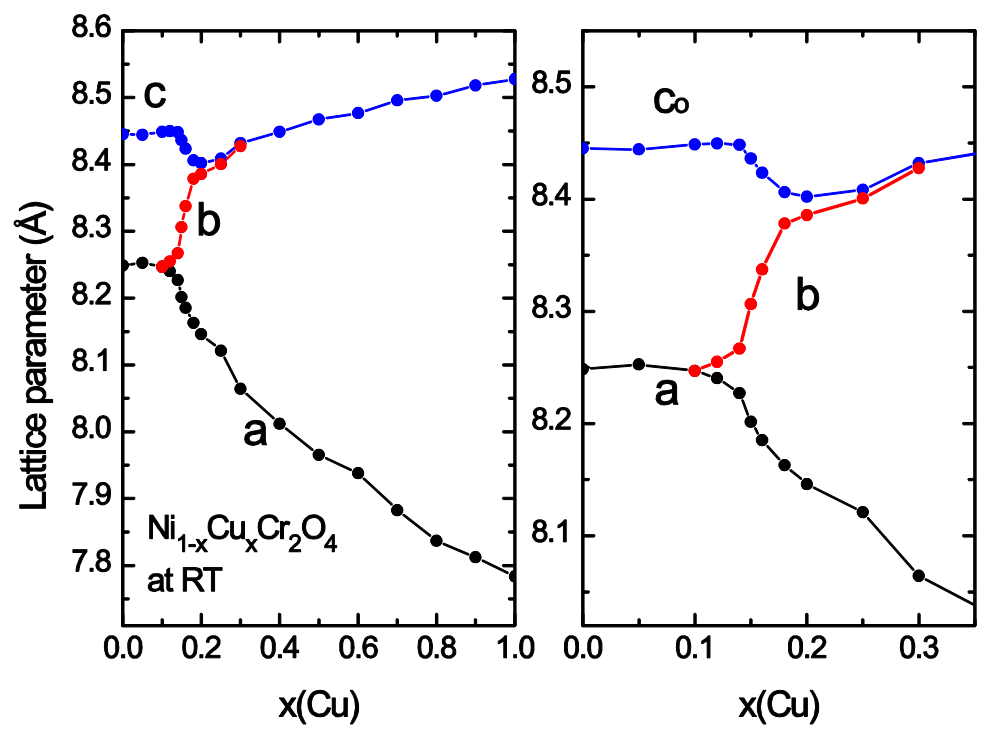

Fig. 2. (Color online) Variation of the lattice parameters in the system $\mathrm{Ni}_{1-x} \mathrm{Cu}_{x} \mathrm{Cr}_{2} \mathrm{O}_{4}$ with increasing copper level as obtained at room temperature from $x$-ray powder diffraction data. A spontaneous change of the lattice parameter $b$ has been observed in the critical range $0.10<$ $x(\mathrm{Cu})<0.20$. 


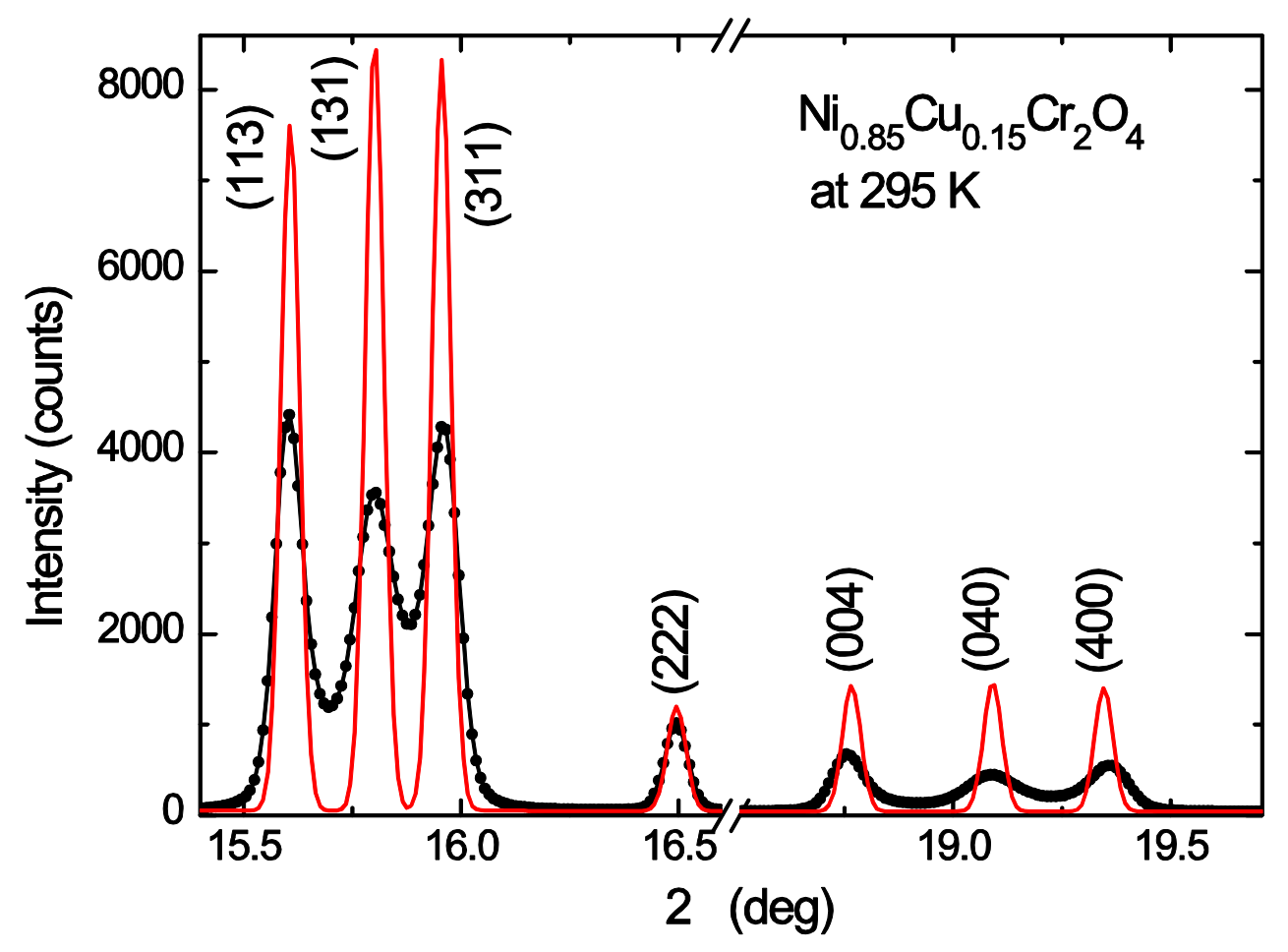

Fig. 3. (Color online) Peak widths of particular reflection series of $\mathrm{Ni}_{0.85} \mathrm{Cu}_{0.15} \mathrm{Cr}_{2} \mathrm{O}_{4}$ as obtained by synchrotron powder diffraction using the wavelength $\lambda=0.6888 \AA$. In order to show the anisotropic broadening of these reflections we used the profile-function parameters obtained from the standard $\mathrm{LaB}_{6}$. The reflection series $h h h$ practically shows the peak shape obtained for $\mathrm{LaB}_{6}$, whereas a strongest peak broadening was observed for the reflections $h 00$, $0 k 0$ and $00 \ell$, respectively. 


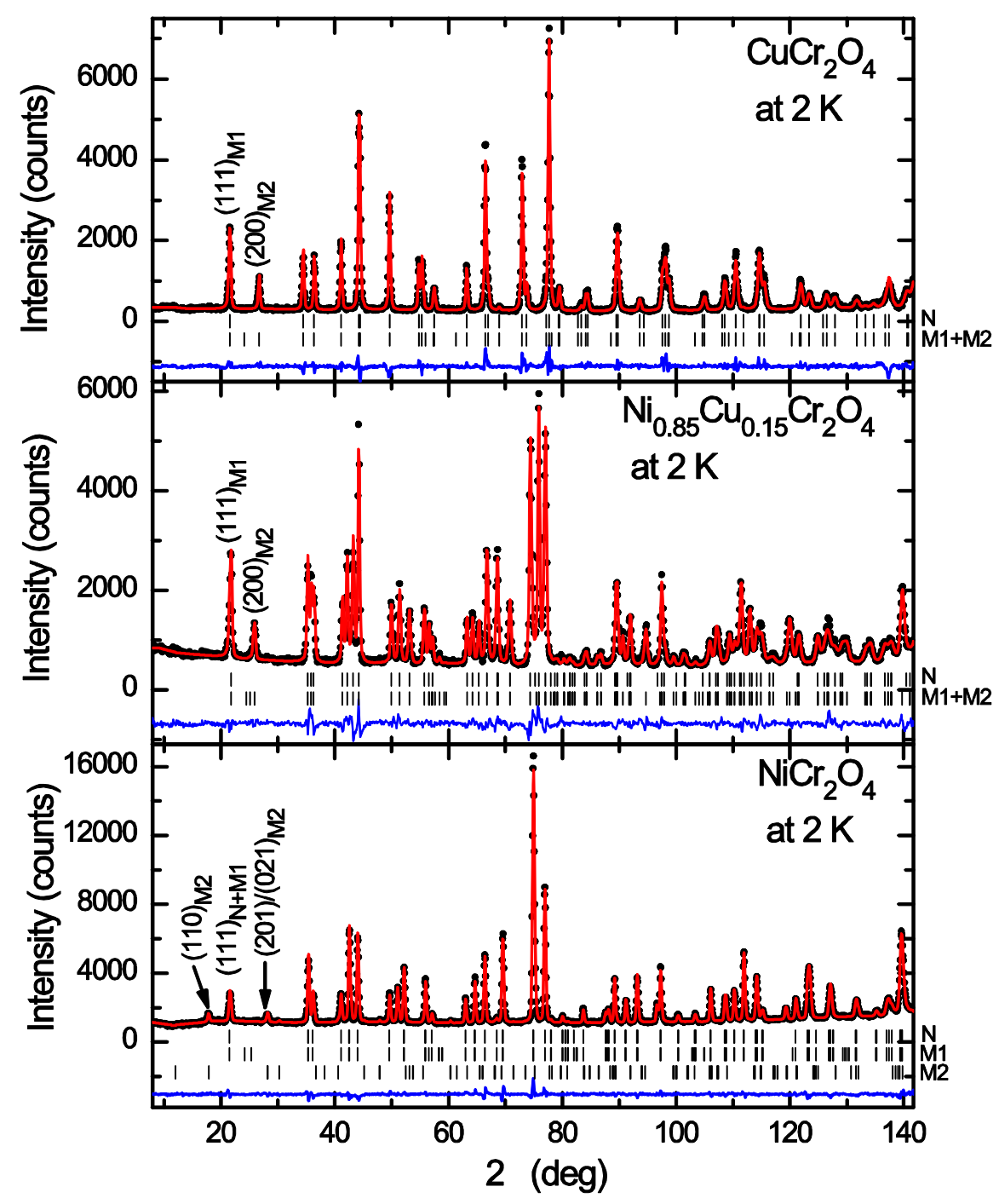

Fig. 4. (Color online) Results of the Rietveld refinements of the neutron diffraction data of $\mathrm{NiCr}_{2} \mathrm{O}_{4}, \mathrm{Ni}_{0.85} \mathrm{Cu}_{0.15} \mathrm{Cr}_{2} \mathrm{O}_{4}$ and $\mathrm{CuCr}_{2} \mathrm{O}_{4}$ collected at $2 \mathrm{~K}$. The crystal structure was refined in the orthorhombic space group $F d d d$. The calculated patterns (red) are compared with the observed ones (black circles). The difference patterns (blue) as well as the peak positions (black bars) of the nuclear $(\mathrm{N})$ and magnetic reflections $(\mathrm{M})$ as well as the difference pattern (blue) are shown. For both $\mathrm{Ni}_{0.85} \mathrm{Cu}_{0.15} \mathrm{Cr}_{2} \mathrm{O}_{4}$ and $\mathrm{CuCr}_{2} \mathrm{O}_{4}$ the ferri- (M1) and antiferromagnetic (M2) structure can be described with the propagation vector $\boldsymbol{k}=0$. In contrast, the antiferromagnetic (M2) structure of $\mathrm{NiCr}_{2} \mathrm{O}_{4}$ has the vector $\boldsymbol{k}=(0,0,1)$. The $h k \ell$ values of the strongest magnetic reflections are given. 


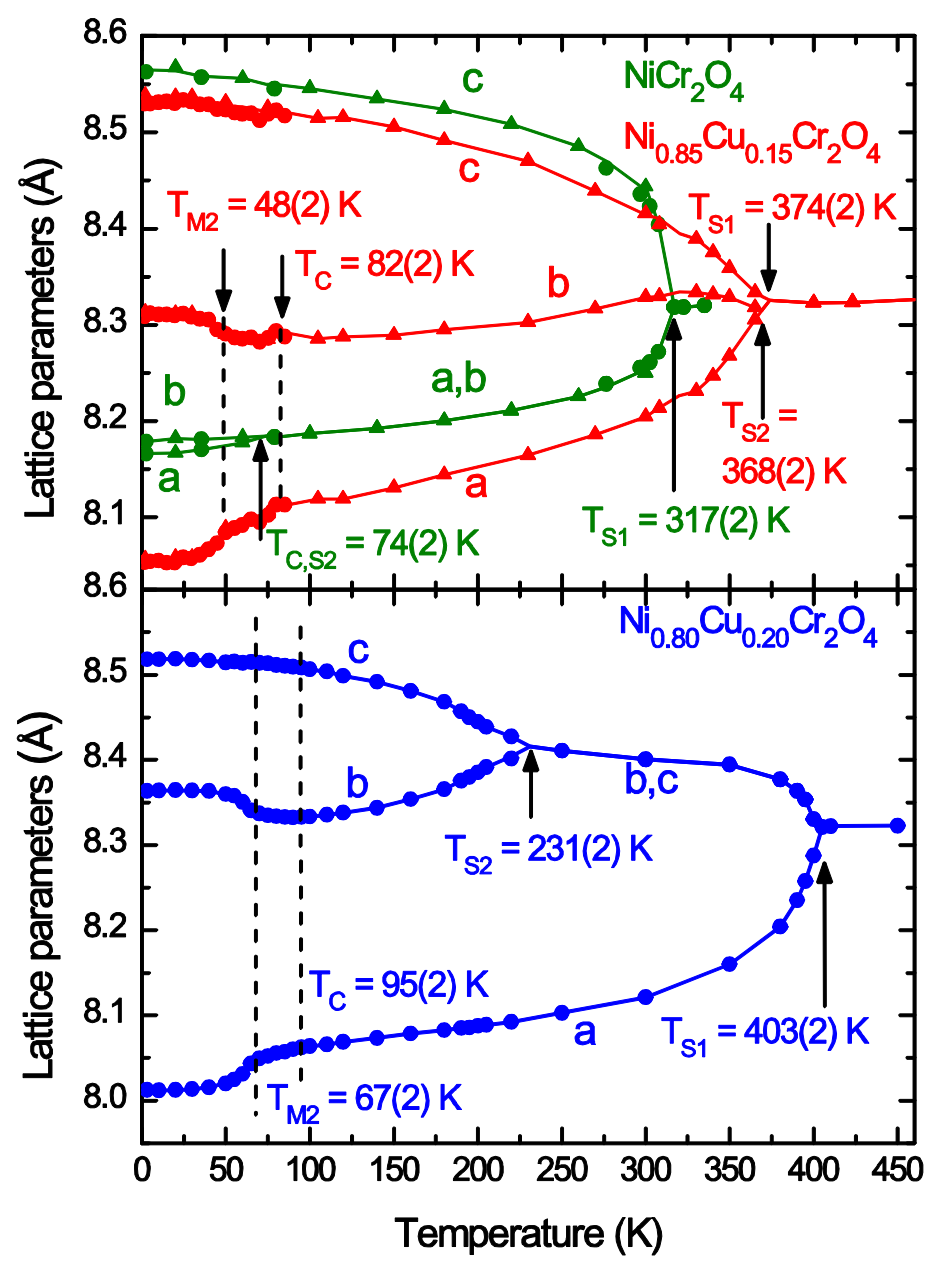

Fig. 5. (Color online) Temperature dependences of the lattice parameters of $\mathrm{NiCr}_{2} \mathrm{O}_{4}$ (green), $\mathrm{Ni}_{0.85} \mathrm{Cu}_{0.15} \mathrm{Cr}_{2} \mathrm{O}_{4}$ (red), and $\mathrm{Ni}_{0.80} \mathrm{Cu}_{0.20} \mathrm{Cr}_{2} \mathrm{O}_{4}$ (blue). The lattice parameters were obtained from $x$-ray (triangles) and neutron powder (circles) diffraction data. With decreasing temperature one finds at $T_{\mathrm{S} 1}$ a structural change from the cubic to the tetragonal spinel-type structure followed by a change into the orthorhombic structure at $T_{\mathrm{S} 2}$. For the end member $\mathrm{NiCr}_{2} \mathrm{O}_{4}$ the second transition sets in concomitantly with the onset of ferrimagnetic ordering $\left(T_{\mathrm{C}}=T_{\mathrm{S} 2}\right)$. At lower temperature a second magnetic transition was observed at $T_{\mathrm{M} 2}$, where one finds for the $a$ and $b$ parameters of $\mathrm{Ni}_{0.85} \mathrm{Cu}_{0.15} \mathrm{Cr}_{2} \mathrm{O}_{4}$, and $\mathrm{Ni}_{0.80} \mathrm{Cu}_{0.20} \mathrm{Cr}_{2} \mathrm{O}_{4}$ strong anomalies due to magnetostriction effects. 


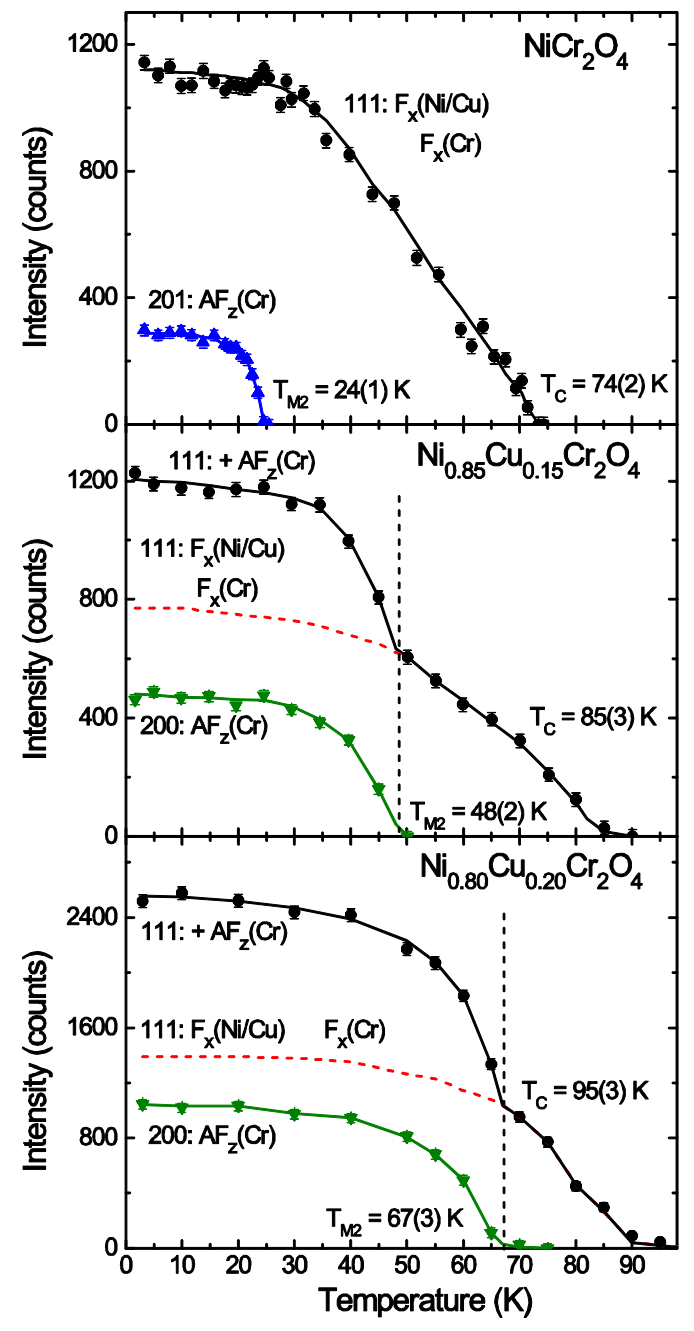

Fig. 6. (Color online) Temperature dependence of magnetic intensity Bragg reflections of $\mathrm{NiCr}_{2} \mathrm{O}_{4}, \mathrm{Ni}_{0.85} \mathrm{Cu}_{0.15} \mathrm{Cr}_{2} \mathrm{O}_{4}$, and $\mathrm{Ni}_{0.80} \mathrm{Cu}_{0.20} \mathrm{Cr}_{2} \mathrm{O}_{4}$. The strongest magnetic phase intensity was found at the position of the reflection 111 indicating a ferrimagnetic spin alignment of the $\mathrm{Ni} / \mathrm{Cu}$ and the $\mathrm{Cr}$ atoms below the Curie temperature $T_{\mathrm{C}}$. Well below $T_{\mathrm{C}}$ the chromium moments show an additional antiferromagnetic ordering at $T_{\mathrm{M} 2}=24(1) \mathrm{K}\left(\mathrm{NiCr}_{2} \mathrm{O}_{4}\right), T_{\mathrm{M} 2}=$ 48(2) $\mathrm{K}\left(\mathrm{Ni}_{0.85} \mathrm{Cu}_{0.15} \mathrm{Cr}_{2} \mathrm{O}_{4}\right)$ and $T_{\mathrm{M} 2}=67(4) \mathrm{K}\left(\mathrm{Ni}_{0.80} \mathrm{Cu}_{0.20} \mathrm{Cr}_{2} \mathrm{O}_{4}\right)$, respectively. The magnetic structure of $\mathrm{NiCr}_{2} \mathrm{O}_{4}$ can be described with the propagation vector $\boldsymbol{k}=(0,0,1)$; those of chromites with a copper level $x(\mathrm{Cu}) \geq 0.15$ with the vector $\boldsymbol{k}=0$. Due to the antiferromagnetic ordering of the chromium moments in the copper containing chromites a spontaneous increase of the magnetic intensity could be observed for the 111 reflection at $T_{\mathrm{M} 2}$. The red dashed line represents the ferrimagnetic contribution of the 111 reflection. 


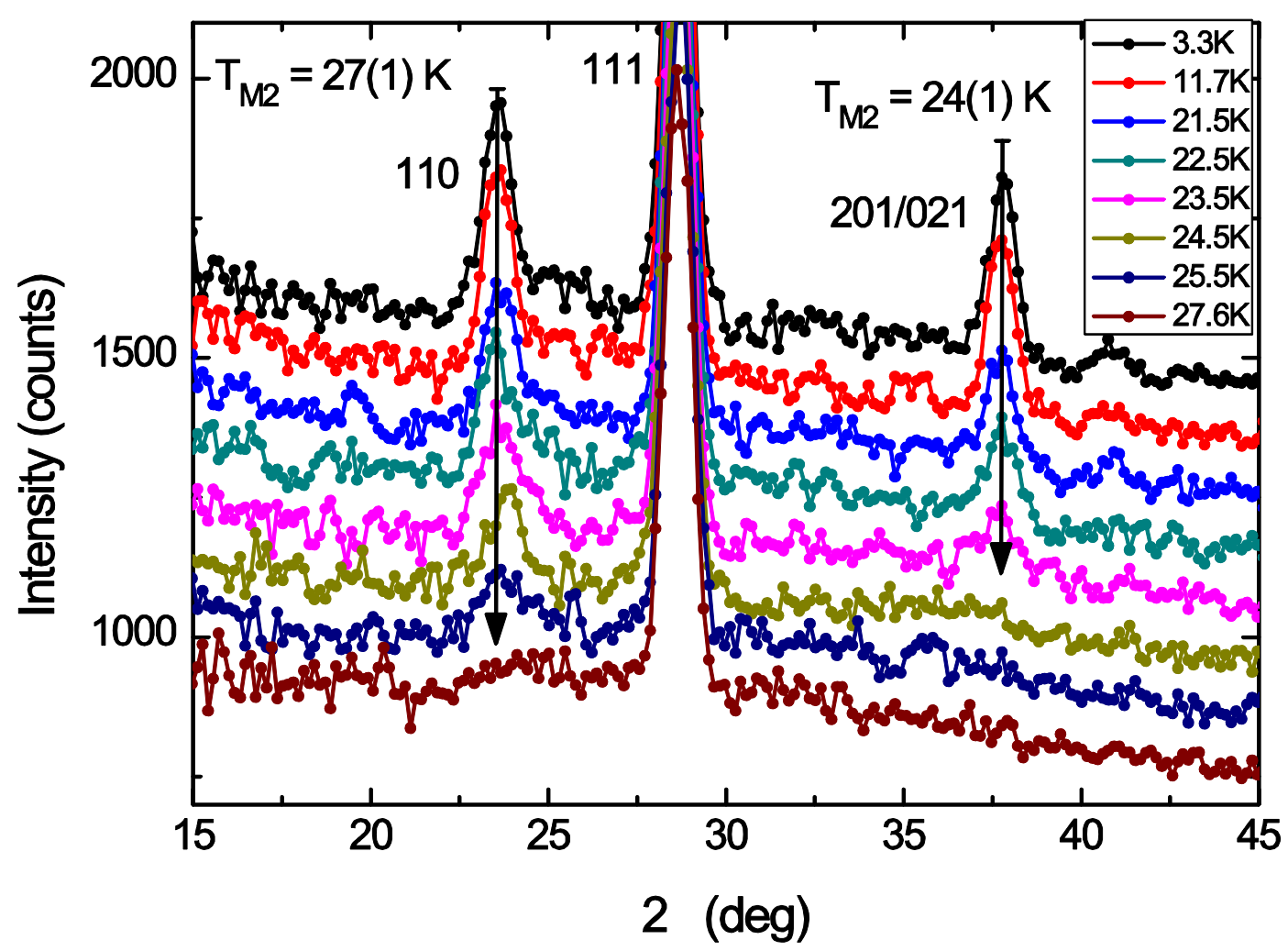

Fig. 7. (Color online) Temperature dependence of magnetic intensity Bragg reflections 110 and 201/021 of $\mathrm{NiCr}_{2} \mathrm{O}_{4}$. Well below $T_{\mathrm{C}}$ the chromium moments show an additional antiferromagnetic ordering at $T_{\mathrm{M} 2}=24(1) \mathrm{K}$. Interestingly the magnetic intensity of the reflection 110 disappears at slightly higher temperature at 27(1) $\mathrm{K}$, possibly due to the presence of diffuse scattering. In agreement with the result of Ref. 35 we also found a very broad magnetic diffuse scattering that gives an uneven background below $2 \theta=45^{\circ}$. 

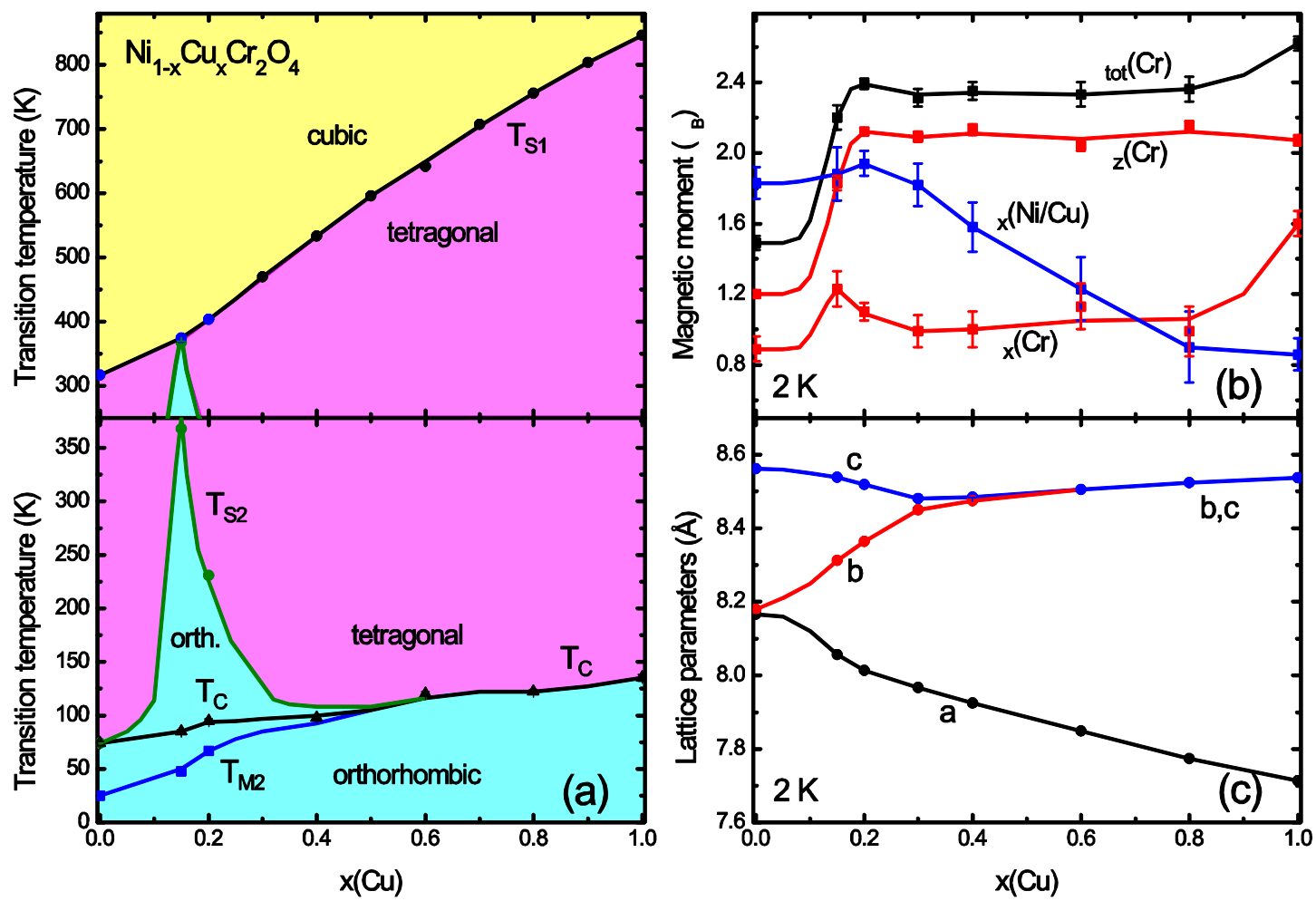

Fig. 8. (Color online) Structural and magnetic phase diagram of the system $\mathrm{Ni}_{1-x} \mathrm{Cu}_{x} \mathrm{Cr}_{2} \mathrm{O}_{4}$. (a) A change from cubic to tetragonal symmetry occurs in the range $317 \mathrm{~K} \leq T_{\mathrm{S} 1} \leq 846 \mathrm{~K}$ (DSCmeasurements: black circles; Neutron diffraction: blue circles). The orthorhombic structure of $\mathrm{Ni}_{0.85} \mathrm{Cu}_{0.15} \mathrm{Cr}_{2} \mathrm{O}_{4}$ is strongly stabilized almost up to $T_{\mathrm{S} 1}$. The transition temperatures $T_{\mathrm{S} 2}, T_{\mathrm{C}}$, and $T_{\mathrm{M} 2}$ have been obtained from our neutron diffraction experiments. The $T_{\mathrm{C}}$ 's of samples with $x(\mathrm{Cu})=0.40,0.60,0.80,1.00$ were determined from earlier magnetization measurements. ${ }^{21}$ The evolution of $T_{\mathrm{S} 2}$ (green bold line) in the range $0.10 \leq x(\mathrm{Cu}) \leq 0.30$ was investigated in detail by Kino and Miyahara. ${ }^{17}$ For the end members $\mathrm{NiCr}_{2} \mathrm{O}_{4}$ and $\mathrm{CuCr}_{2} \mathrm{O}_{4}$ the crystal structure changes to a lower orthorhombic structure at the Curie temperature $T_{\mathrm{C}}=$ $74 \mathrm{~K}$ and $T_{\mathrm{C}}=135 \mathrm{~K}$, respectively. For the Ni-rich chromites a splitting into two magnetic transitions ( $T_{\mathrm{C}}$ and $T_{\mathrm{M} 2}$ ) was found. (b) Evolution of the magnetic moments of the $\mathrm{Ni} / \mathrm{Cu}$ and the $\mathrm{Cr}$ atoms in the system $\mathrm{Ni}_{1-x} \mathrm{Cu}_{x} \mathrm{Cr}_{2} \mathrm{O}_{4}$. (c) Evolution of the lattice parameters in the system $\mathrm{Ni}_{1-x} \mathrm{Cu}_{x} \mathrm{Cr}_{2} \mathrm{O}_{4}$. The bold solid lines in all diagrams are guides for the eye. 


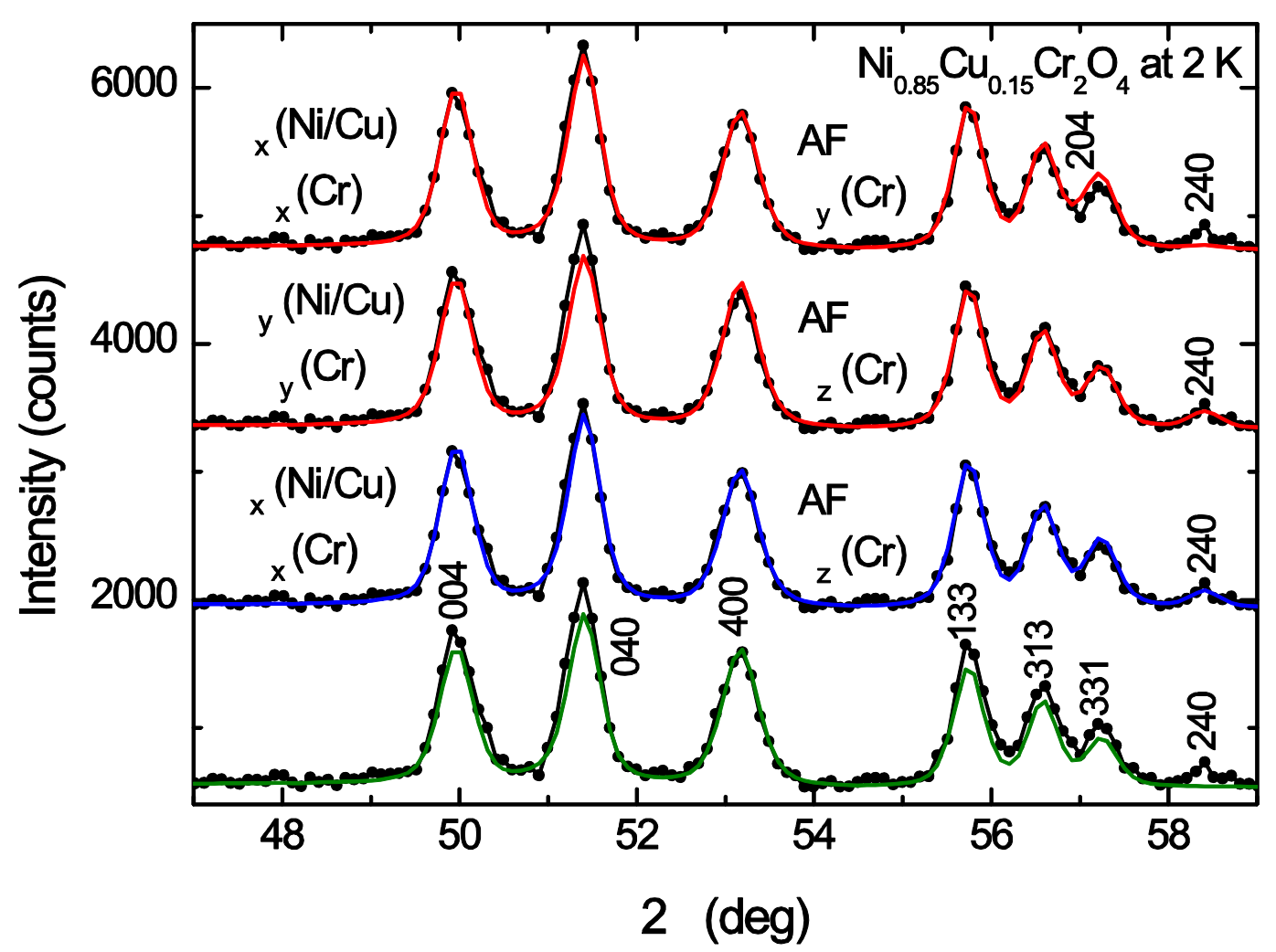

Fig. 9. (Color online) Rietveld refinements of the neutron diffraction data of $\mathrm{Ni}_{0.85} \mathrm{Cu}_{0.15} \mathrm{Cr}_{2} \mathrm{O}_{4}$ collected at $2 \mathrm{~K}$. The calculated patterns (red/blue/green lines) are compared with the observed ones (black circles, black lines). In the lower part of the plot only the contribution of the nuclear intensity (green) is shown. The red lines in the upper two diagrams additionally include the calculated magnetic intensities of the two models, where ferri- and antiferromagnetic ordering occur in the $x y$ and $y z$ planes, respectively. Finally the best fit was obtained for the model, where ferri- and antiferromagnetic ordering occurs along the $x$ and $z$ directions (blue line). 

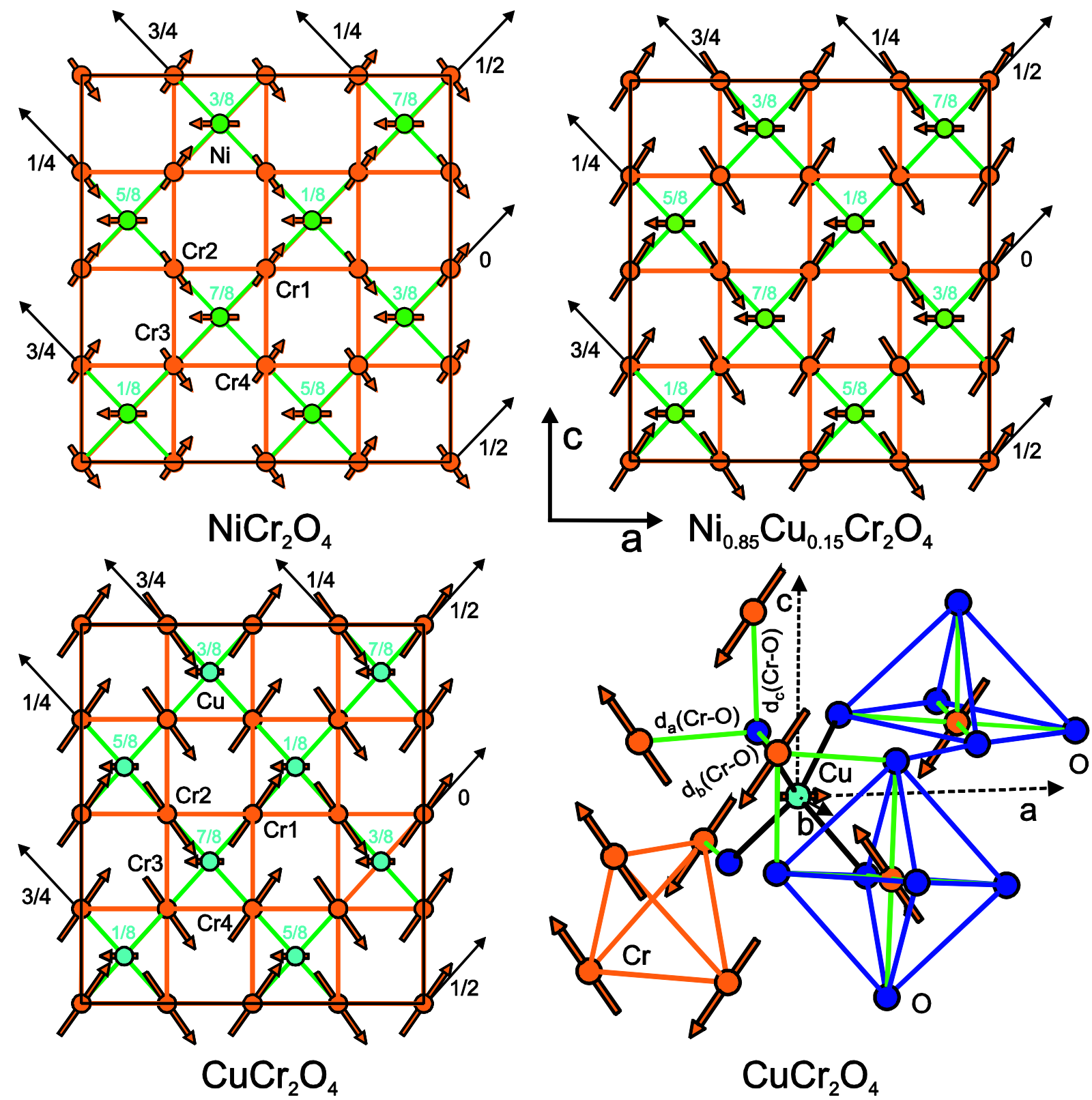

Fig. 10. (Color online) Magnetic structures of $\mathrm{NiCr}_{2} \mathrm{O}_{4}, \mathrm{Ni}_{0.85} \mathrm{Cu}_{0.15} \mathrm{Cr}_{2} \mathrm{O}_{4}$, and $\mathrm{CuCr}_{2} \mathrm{O}_{4}$ at 2 $\mathrm{K}$. The chromium atoms form chains along the [110] and [1-10] directions (black arrows) at $y$ $=0,1 / 4,1 / 2$, and 3/4, respectively. Ferrimagnetic ordering of the $\mathrm{Ni} / \mathrm{Cu}$ and $\mathrm{Cr}$ atoms sets in below $T_{\mathrm{C}}$, where the moments are aligned parallel to the $a$ axis. An additional antiferromagnetic component was found to be parallel to the $c$ direction resulting in noncollinear frustrated magnetic structures, where the $\mathrm{Cr}$ atoms in the antiferromagnetic state $\left[(\mathrm{Cr} 1)^{1 / 2,1 / 2,1 / 2} ;(\mathrm{Cr} 2)^{1 / 4}, 1 / 4,1 / 2 ;(\mathrm{Cr} 3)^{1 / 4}, 1 / 2,1 / 4(\mathrm{Cr} 4)^{1 / 2,1 / 4,1 / 4}\right]$ show the spin sequence +--+ . On the bottom right the network of $\mathrm{CrO}_{6}, \mathrm{CuO}_{4}$ and $\mathrm{Cr}_{4}$ polyhedra in $\mathrm{CuCr}_{2} \mathrm{O}_{4}$ is shown. 